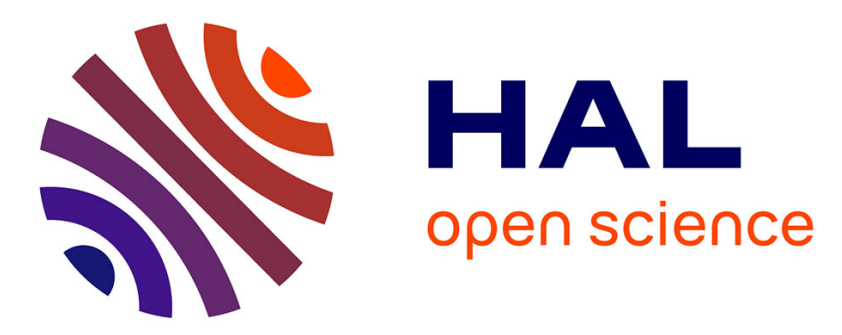

\title{
Simulation of a helicopter's main gearbox semiactive suspension with bond graphs
}

Benjamin Boudon, François Malburet, Jean-Claude Carmona

\section{To cite this version:}

Benjamin Boudon, François Malburet, Jean-Claude Carmona. Simulation of a helicopter's main gearbox semiactive suspension with bond graphs. Multibody System Dynamics, 2016, 39 (1), pp.60-64. hal-01430117

\section{HAL Id: hal-01430117 https://hal.science/hal-01430117}

Submitted on 9 Jan 2017

HAL is a multi-disciplinary open access archive for the deposit and dissemination of scientific research documents, whether they are published or not. The documents may come from teaching and research institutions in France or abroad, or from public or private research centers.
L'archive ouverte pluridisciplinaire HAL, est destinée au dépôt et à la diffusion de documents scientifiques de niveau recherche, publiés ou non, émanant des établissements d'enseignement et de recherche français ou étrangers, des laboratoires publics ou privés. 


\title{
Simulation of a helicopter's main gearbox semi-active suspension with bond graphs
}

\author{
Benjamin BOUDON, François MALBURET, Jean-Claude CARMONA
}

\begin{abstract}
This paper presents a bond graph model of a helicopter's semi-active suspension and the associated simulations. The structural and modular approach proposed with bond graph permits a systematic modeling of mechatronic multibody systems. The model is built as an assembly of components or modules (rigid bodies and kinematic joints) by following the structure of the actual system.

The bond graph model of the passive suspension with fixed flapping masses has been verified with another multi-body tool for three different excitations (pumping, roll and yaw). Next, the passive model, augmented with electrical actuators and controllers, is called the semi-active suspension model. Simulations on the semi-active suspension model have been conducted.
\end{abstract}

Keywords Multibody systems (MBS), Closed kinematic chain (CKC), Bond graph (BG), Helicopter, Mechanical vibrations, 20-sim

\section{Introduction}

Mainly due to the operation of the rotor, the helicopter is subject to important vibration levels affecting namely the flight handling, the fatigue of the mechanical parts and the crew's comfort. The considered vibrations created by the aerodynamic and inertia forces acting on the rotor excite the main gearbox and next the fuselage at a specific frequency $b \Omega$ where $b$ is the number of blades of the main rotor and $\Omega$ the rotational velocity of the main rotor. Suspensions between the main gear box (MGB) and the fuselage help to filter theses problematic vibrations. Different passive technical solutions exist for the completion of this joint. In this paper, the MGB-Fuselage suspension with a SARIB system (Suspension Antivibratoire à Résonateur Intégré dans les Barres in French) is studied. This anti-vibratory system creates an anti-resonance phenomenon at the $b \Omega$ frequency. The principle of this system will be described in section 2. Even if the passive SARIB MGB-Fuselage suspension is efficient compared to more classical suspensions such as flexible suspension, the passive solutions show their limits when different types of external forces (pumping force and roll / pitch torque) are combined and when some fluctuations of the variable engine speed occur during the flight. So, to address these challenges, intelligent active solutions are proposed so that the filtering can be adjusted according to the vibration sources.

The studies of such systems still suffer from a lack of tools and methods that are necessary to the design of complex mechanical systems and also to the development of an intelligent joint. The system model is a complex mechatronic multi-body system (according to definitions given in [1]) because of the numerous bodies and joints, the mechanical forces applied on the MGB, and the presence of several kinematic loops and electronics actuators. The design and the analysis of such complex systems are usually conducted with analytical methods based on physical equations or signal-flow methods based on transfer functions written on a block diagrams form. Unfortunately, these two classical approaches may cause a loss of the physical sense and the visibility of the modeling assumptions [2, 3]. Moreover, reusing models and taking account increasing complexity can be cumbersome and prone to errors because of the need of manual transformations so as to build physics-based model libraries with block diagrams [3].

In this context, we present a bond graph (BG) approach [4] that permits a structural and modular approach of a complex mechatronic system. These well-known features [5, 6]: graphic, object-oriented, multiphysic and acausal can be exploited for this class of multibody system with embedded electronics. Mainly with its graphical nature, the bond graph brings a more global view and comprehension of complex mechatronic system which lead to more sustainable solutions. Based on oriented-object and acausal features, bond graphs also permit a modular approach which allows a better knowledge capitalization to better store and reuse your modeling works. Moreover, it would facilitate the automation of the modeling task. Particular attention will be given in showing the interest of the bond graph tool relative to more conventional tools. 
In the 90's, thanks to the multibond graph formalism (an extension of bond graphs where the scalar power bonds become vectors bonds and the elements multiports), the bond graph was extended to the study of multibody systems with three dimensions [7] [8]. Nevertheless, few complex multibody systems with kinematic closed loops have been simulated. In the last twenty years, computer science and software dedicated to bond graphs such as 20sim software ${ }^{1}$ have considerably progressed and give back many interest to bond graph [9]. First, the graphical aspect of bond graph can be fully exploited. Indeed, friendly environments enable the entering, modifying or interpreting of bond graphs. Secondly, the automatic generation of equations from a bond graph enables the engineers to avoid the solving equations. Consequently, this step is less cumbersome and prone to errors. Moreover, the simulation software mentioned are now equipped with performing numerical solvers.

The MGB-Fuselage suspension with SARIB system studied here is a complex mechanical closed kinematic chain (CKC) system. The dynamics equations of such a CKC system are a differential-algebraic equation systems (DAE) which are difficult to treat and which require specific solving methods. The method of singular perturbations [10] [11] [12] used in this paper appears to be an elegant and easy solution to derive the simulation of a CKC system.

This paper has two main objectives. The first one is to model and simulate a helicopter semi-active suspension between the main gear box (MGB) and the aircraft fuselage with bond graph. The second one is to show that bond graphs allow the modeling of such a class of systems with a structural and modular approach.

The paper is organized as follows. In section 2, we present the context and purpose of the suspension studied. Section 3 details the modeling and simulation framework based on a bond graph approach. Section 4 describes first the kinematic structure and the mechanical assumptions retained for the suspension model. Secondly, the modeling and simulation framework is applied and the bond graph model of passive suspension is detailed. Simulation results and a validation based on experimental results will be presented in Section 5. Finally, the conclusion will be given in the last Section.

\section{Overview of the MGB-Fuselage suspensions}

\subsection{Context}

The rotor of a helicopter is a powerful vibration generator that can generate various vibration phenomena. Let us consider:

- forced vibrations,

- resonances "ground and air",

- dynamic problems of the power chain.

Blades undergo periodic and alternating inertia and aerodynamic forces whose fundamental frequency is the rotation frequency of the rotor as explained in [13]. These efforts on the blades cause forces and torques on the hub which then becomes a mechanical excitation of the fuselage. It is always shown in [13] that these forces and moments transmitted from the rotor to the fuselage have frequencies whose are frequency harmonics $(\mathrm{kb} \Omega)$ with $\mathrm{b}$ the number of blades of the main rotor and $\Omega$ the rotation speed of the main rotor. Moreover, most of the time, the first harmonic $b \Omega$ is preponderant.

Therefore, its behavior depends on its dynamic characteristics and the filtering systems placed between the rotor and the fuselage (as shown in Fig. 1). In this sequel, we will focus on one of these filtering systems: the SARIB system (called Suspension Antivibratoire à Résonateur Intégré dans les Barres in French).

\footnotetext{
${ }^{1}$ http://www.20sim.com/
} 


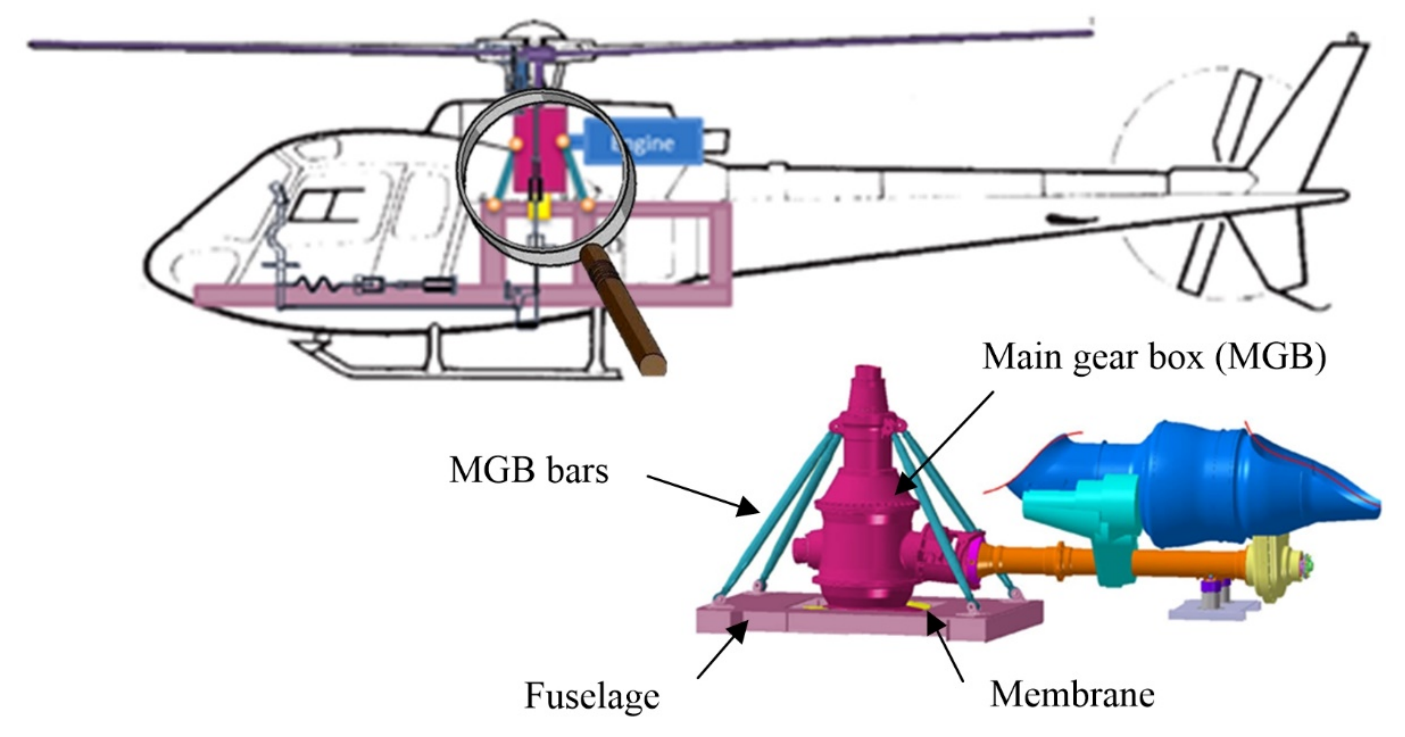

Fig. 1 - Helicopter suspension between the MGB and the aircraft structure

\subsection{Interest and functions}

The MGB-Fuselage suspension must ensure several important functions. Firstly, the joint allows the transmission of the static force necessary to the sustentation of the helicopter with a limited static displacement. Moreover, the suspension helps to reduce the mechanical vibrations transmitted to the fuselage according to the force and displacement aspects. In this paper, we will focus on this latter function.

\subsection{Operating principle}

The classical MGB-Fuselage suspension is composed of four MGB bars and a main membrane as shown in Fig. 2a. The MGB bars can rigidly suspend the fuselage without flexibility to the rotor and thus transmit the lift from the rotor to the structure.

The membrane is a flexible suspension with the following observed behavior:

- a low stiffness for angular movements around the roll and pitch axes and the linear vertical pumping displacement,

- a very high stiffness for linear movements perpendicular to the vertical direction and for the yaw movement.

Thus, the membrane allows the angular movement of the MGB around the pitch and roll axes. The flexibility of the membrane around these axes allows a strong filtration of the dynamic moments around these axes. In addition, the membrane transmits the main rotor torque thanks to its very high stiffness around the yaw axis. In conclusion, the conventional suspensions allow filtering pitch and roll dynamic moments without filtering the pumping dynamic efforts.

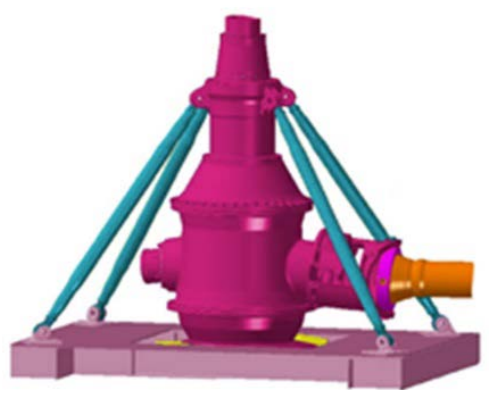

(a)

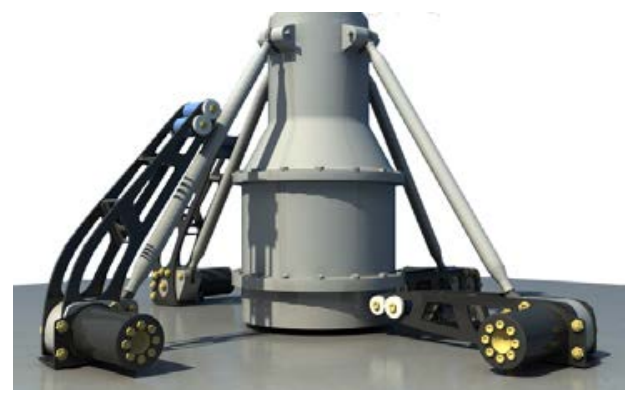

(b)

Fig. 2 - (a) Flexible classical MGB-Fuselage suspension, (b) MGB-Fuselage suspension with SARIB system. 
The suspension equipped with SARIB system is a vibration absorber. Its purpose is to render the filtering of these pumping dynamic efforts possible. On the SARIB solution, beaters with flapping masses are added between the MGB bars and the fuselage Fig. 2b. They permit a vertical degree of freedom to the MGB with regard to the fuselage. The principle of the SARIB system is to tune, for an accurate defined frequency, these flapping masses on each SARIB bar so as to create inertial forces on the fuselage opposite to the force of the MGB bars on the beaters. The equilibrium of a SARIB bar enables to better understand this principle. In other words, there is an anti-resonance phenomenon on the transmissibility function between the excitation applied to the MGB. Hence, the forces transmitted to the fuselage can be strongly reduced at this anti-resonance frequency.

In the semi-active suspension, the flapping masses on the beaters can be translated and be consequently called tuning masses. The idea of the semi-active suspension will be to tune the positions of the moving masses so that the anti-resonance frequency of the structure corresponds to the frequency of the excitation forces on the MGB.

\subsection{Overview of the experimental setup}

According to helicopters engineers, two types of experiments can be conducted in order to test the flight behavior of the MGB-fuselage system: either directly on a helicopter or on an experimental setup. The first type of test is more expensive and is carried out mainly in the validation phase of the system. The research work presented in this paper is focused on the pre-sizing phase.

It was thus decided to develop an experimental setup on a small scale so as to conduct the experimental tests. The geometry and mass properties correspond to a light helicopter with a scale of approximately $1 / 2$ (see appendix). The models proposed in this paper have been simulated with the data of this experimental setup. This experimental setup preserves the 3D feature of the real system by the use of four MGB bars. It allows the simulation of a semiactive system with SARIB beaters equipped with tuning masses. The experimental setup has to represent the flight behavior of the helicopter in different operating phases: hover, up / down or turn. In these operating phases, the MGB is subjected to pumping, pitch and roll excitements. On the experimental setup, the rotor action, provided by the aerodynamic forces and the blades stiffness, applied to the MGB will be approximated by a sinusoidal excitation at the frequency $b \Omega$ obtained with a vibration equipment.

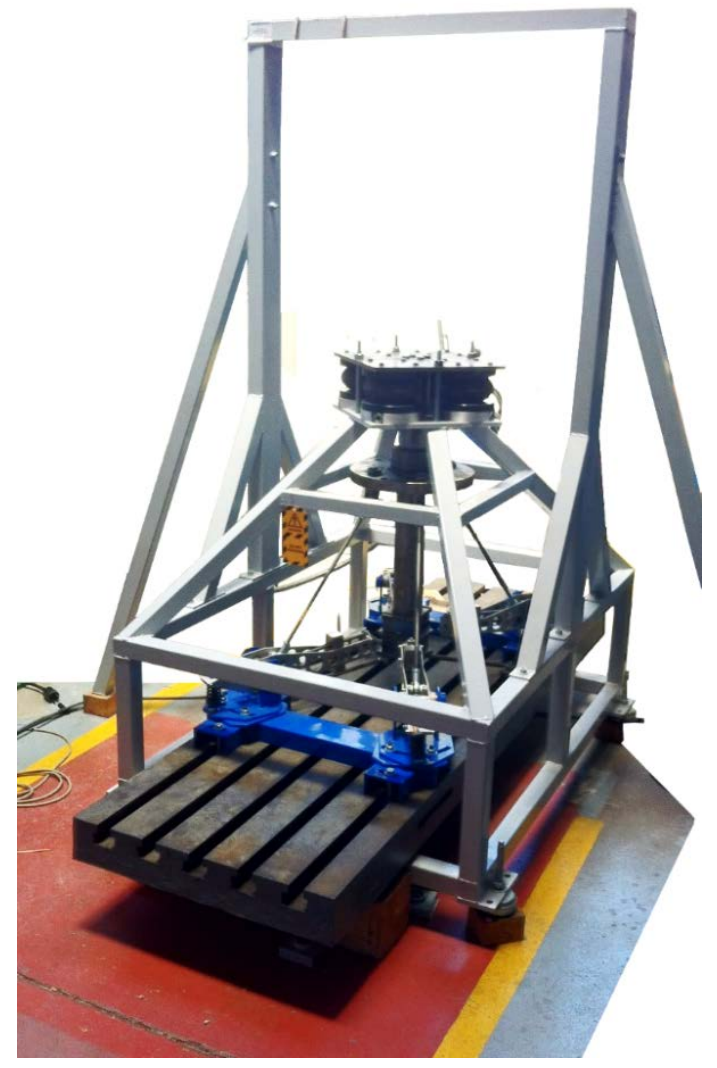

Fig. 3 - Experimental setup of the semi-active suspension 


\section{Modeling and simulation framework}

\subsection{Classical bond graph modeling}

\subsubsection{Brief review}

The concept of energy is fundamental in the description of the evolution of technological systems. Energy is present in all areas of physics and is the link between them. From this observation, a number of tools with energetic representations for modeling complex systems have been defined. One of the main tools is the bond graph. The bond graph was created by H. Paynter [4] in 1959 and developed by R. Rosenberg and D. Karnopp [14] in the United States.

The bond graph is based on a study of the transfer of power in a system modeled by lumped parameters. The bond graph is a graphical modeling tool that covers all physical systems (mechanical, hydraulic, electronic, thermal...) regardless of their condition (linear, nonlinear, continuous ...). It is represented as an oriented graph showing dynamic variables and power bonds between these variables. The bond graph systematically associates two different variables for each bond: a generalized effort variable (which is a force or a torque in mechanics) and a generalized flow variable (which is a translational or rotational velocity in mechanics) on each side of the halfarrow link. Each bond has therefore power information, obtained by the product of these two variables, and allows direct access to the energy transferred by a simple integration of power. The bond graph approach enables thus, the representation of mechatronic systems in a graphical form that describes the exchange of power between basic elements like inertia, compliance, dissipation, conservative power transformation, gyrator actions and sources.

More details on bond graphs can be found in $[5,6]$ on the basis, the operation and the construction of classical bond graphs. The classical bond graphs mentioned in this paragraph 3.1 also called 1D bond graphs deals with mechatronics system with elementary motions (translation and rotation around fixed axis) and without 3D movement.

\subsubsection{Benefits of bond graphs}

The major benefits of bond graphs developed mainly in [5] [6] are well-known in mechatronics communities. They are thus only recalled here but not detailed for space reasons. As mentioned previously, the bond graph is a unified and energetic language covering almost all physical domains. The bond graph facilitates a systemic approach necessary to design a mechatronic system thanks to its features as graphical display, object-oriented language and acausality (in a similar manner as Modelica [15]).

In addition, bond graphs also enable the use of new features such as structural analysis [16] of a system from the bond graph structure (causality, controllability, observability, inversibility, etc). While these characteristics is not utilized in this paper, the exploitation of bond graphs is mentioned here since it constitutes of a perspective of this work.

\subsection{Modeling of multibodies system with bond graphs}

\subsubsection{Brief review}

The aim of this section is to recall the main contributors concerning methodologies for modeling the dynamics of three-dimensional multibody systems (MBS). More detailed reviews specifying applications of BG modeling for MBS can be found in [5], [6] and [17].

The first bond graph models of multibody systems have been proposed by D.C Karnopp and R.C Rosenberg $[18,19]$ thanks to an analytical approach based on an appropriated choice of generalised coordinates, the construction of junction structure for the formulation of the kinematic laws and a lagrangian formulation.

In the 90's, thanks to the multibond graph (MBG) formalism [20] [21] (an extension of bond graphs where the scalar power bonds become vector bonds and the elements multiports), the application fields of the bond graph were extended to the study of multibody systems with three dimensional movements.

The bond graph approach used for multibody systems was introduced by A. M. Bos [7, 8]. In his PhD, he developed bond-graph models for three-dimensional multibody systems and discussed how to derive the equations of motion from the bond-graph in several different forms. At this time, although he managed to conduct simulations of a 3D motorcycle, the equations had been derived with a manual process. 
Library models for a rigid body and for various types of joints have been provided in [10] so that bond graph models of rigid multibody systems can be assembled in a systematic manner.

J. Felez [22] developed a software that helps with modeling multibody systems using bond graphs. To handle derivative causalities with this software, he proposes a way to introduce Lagrange multipliers into the system so as to eliminate derivative causality.

In [23, 24], different methods for simulating BG models have been presented. Simulations have been conducted with a predecessor of 20-sim software and numerically compared mainly on the computing time and accuracy. Even if the possibility of using multibond graph was evocated, the difficulty of implementing bond graphs with vector bonds were not mentioned.

Furthermore, W. Marquis-Favre and S. Scavarda [25] propose a method to simplify bond graph models for multibody systems with kinematic loops. Nevertheless, few complex multibody systems with kinematic closed loops have been simulated.

\subsubsection{Discussion on the use of bond graphs for multibody systems}

In [6], [26], some difficulties in using bond graphs for multidomain applications namely multibody systems have been pointed out. Even if some of these difficulties such as ( the use of frame-dependent vectors and generation of constraints at velocity level) are persistent, other points described hereafter have been improved or solved thanks to the evolution of dedicated software for bond graphs and the use of appropriated methods.

Firstly, the multibond graph allows to simplify the bonds between the bond graph elements and the readiness of the model. Nevertheless, the causality analysis of multibond graphs can be considered as a difficult task as mentioned in [6]. Multibond graphs do lead to causality constraints as mentioned in [27] and [28]: 1) each dimension of a vector bond must have the same causality, 2) the causality of transformers implied in cross product and the causality of gyrators is imposed. However, some methods for dealing with these two constraints (namely singular perturbations or Lagrange multipliers, ...) have been proposed [27] and are efficient to resolve these difficulties.

Secondly, thanks to the use of the word bond graph (WBG), the multilevel representation is permitted and allows for the concatenation of the bond graphs' bodies and joints. This technique makes it possible to "zoom in / out" on different parts of the system, such as in a Simulink model. However, with bond graphs, the hierarchical decomposition is not made in mathematical functions as in block diagrams but in models of subsystems. As defined in [5], the structural models are defined as an assembly of models of physical elements or subsystems following the same architecture as the real system without prior analysis on how to connect the various subsystems. From the authors' points of view, bond graphs thus belong to this class of structural modeling tools. As a consequence, it is possible to obtain a global representation of the system built from subsystems which facilitates the management of interactions and/or couplings.

Thirdly, the modularity allowed by the bond graph method enables the model to evolve and meet the levels of complexity required for each design problem by the addition or modification of new components and subsystems and by replacing behavior laws.

Fourthly, even if it is true that bond graphs for multibody systems require a certain level of expertise, the generation of equations from the bond graph models can be done automatically by dedicated softwares to bond graphs such as 20-sim and even for complex bond graph models as it will be shown in this paper through the MGB-Fuselage suspension. Naturally, it is important to note that methods such as the singular perturbation method used in this paper must be used to tackle constraints due to vector bonds and derivative causalities which can appear on some inertial elements.

\subsubsection{Approach chosen : the BOS and Tiernego method}

In order to keep a modular approach, the principal method for modeling multibody system with bond graphs is the Bos and Tiernego method [7]. This method enables a multibody system to be built as an assembly of bodies and joints. The principle of this method is based on the use of absolute coordinates systems and Newton-Euler equations. Indeed, in such a way, the dynamic equations of a rigid body depend on, obviously, his mass/inertia parameters and also on geometric parameters defined only for the considered body. Consequently, the dynamic equations of the complete system consist of a sum of the dynamic equations of each body depending only on its own parameters. 


\subsection{MBG modeling of closed kinematic chains (CKC)}

\subsubsection{Problem statement}

The simulation of mechanical systems with kinematic loops requires specific methods. This difficulty does not come from the bond graph tool but from the application of dynamics equations to such systems where some kinematic variables are linked together because of the kinematic constraints. Regardless the analytical method employed (fundamental principle of dynamics or Lagrange equations with multipliers), when no preliminary kinematic works is done, the equations obtained are differential algebraic equations (DAEs) whose numerical resolution requires specific numerical integration methods. In bond graphs, this class of constrained mechanical systems that leads to differential-algebraic equations present inertial elements with derivative causality whose variables are dependent on others variables considered as independent through algebraic constraints.

In this paper, in order to keep a modular approach as mentioned in the previous section, absolute coordinates are selected. Consequently, in this case (absolute coordinates selected), it is important to notice that open chain (OC) and closed kinematic chain (CKC) systems both lead to a DAE formulation. Consequently, one of the necessary priorities of the simulation method exposed in this paper will be to handle DAEs.

\subsubsection{Resolution methods}

These difficulties to solve numerically differential equations are developed, for example, in W. Marquis-Favre [29]. A recent and concise review of the methods for solving DAEs can be also found in [30]. To sum up, one can find three groups of methods: the direct resolution of the DAE thanks to specific solvers, the reduction of the DAE in an ODE like the coordinates partitioning method or minimal coordinates and the conversion to an ODE by modifying the model system. The singular perturbation method which is used in the paper belongs to the last category of these methods that is to say the conversion to an ODE by modifying the model system.

\subsubsection{Approach chosen : the singular perturbation method}

The bond graph simulation with the singular perturbation method is quite easy to implement compared to conventional techniques used during an analytical study. We thus decided to use the method of singular perturbation which, from our point of view, keeps a physical insight and permits to keep a modular approach without the need to use additional stabilization techniques to circumvent the drift of the constraints.

The singular perturbation method consists in augmenting the bond graph of the joints with parasitic elements [31] [32] also called virtuals springs in [12]: stiffness and damping elements corresponding to C energy store element and $\mathrm{R}$ resistive element.

The enforcement of constraints through parasitic $\mathrm{C}$ and $\mathrm{R}$ elements instead of using ideal flow sources can circumvent the two multibond constraints mentioned in 3.2.2 thanks to the effort-out causality permitted by the parasitic elements. Firstly, it allows the same causality assignments for all the bonds of a multibond. Secondly, it allows to suppress the causality conflict which may appear because of the imposed causality of the transformers implied in the cross product and gyrators [27].

If the kinematic constraints modeled by the bond graph where the joints are rigidly imposed, derivative causality appears at the multibonds connected to the translational inertia elements. The derivative causality, due to constraints, requires that the equations derived from the bond graphs to be differential algebraic equations (DAEs). The resolution of such equations is quite complex from a computational point of view as we explained before. The singular perturbation method relaxes the kinematic joint constraints. The dynamic equations are in an ODE form with no geometric constraints to deal with. It leads thus to a bond graph with integral causality which can be simulated easily using explicit solvers.

The values of the compliant elements must be chosen carefully. To our knowledge, two methods for selecting these elements exist : 1) the eigenvalues decoupling between the parasitic frequency and the system frequency, 2) the use of activity metric [31]. These parameters can be chosen so as to model the joint compliances which exist in all mechanical joints. Thus, this point gives to this method a physical significance. The stiffnesses introduced should be high enough so as not to change the dynamic of the system but not too high so as to prevent the numerical difficulties of stiff problems (with high-frequency dynamics). This method leads to a necessary compromise between the accuracy of the results and the simulation time: the stiffer the system is, the more numerical errors are reduced but the more simulation time remains important. However, the increase of the simulation time can be balanced by parallel processing as the mass matrix in a block-diagonal form can enable to decouple the system as 
it is explained in [12]. As T. Rayman recommends, adding a damping element (R resistive element) in parallel with the stiff spring ( $\mathrm{C}$ energy store element) enables to dampening of the high eigen frequency associated with the high stiffness. The exact influence of these parameters still remains a research work in which the authors are particularly interested in.

\section{Modeling of the passive suspension}

The bond graph modelling steps described above will now be applied to model the MGB-fuselage suspension equipped the with SARIB device. First, the mechanical model of the MGB-fuselage suspension and the associated assumptions will be presented. Secondly, the construction of the bond graph model of the MGB-fuselage suspension will be detailed.

\subsection{Modeling assumptions of the MGB-Fuselage suspension}

The 3D MGB-fuselage suspension with free fuselage is a set of 14 rigid bodies (the MGB, four MGB bars, four SARIB beaters, four intermediate bodies and the fuselage) and includes eighteen kinematic links (four revolute joints, eight spherical joints and two prismatic joints). The kinematic scheme of the 3D MGB-fuselage suspension is shown in Fig. 4.

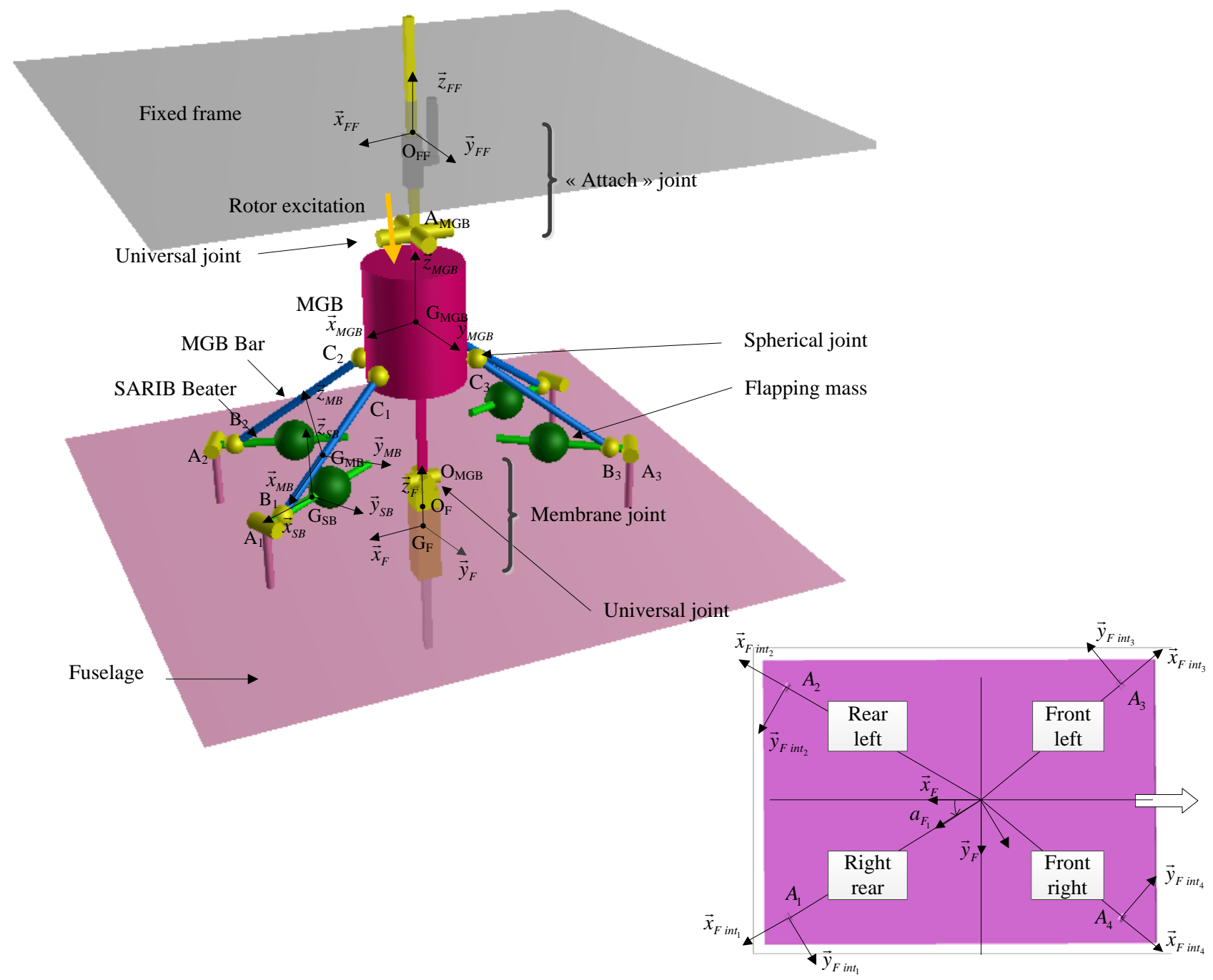

Fig. 4 - Kinematic scheme of the 3D joint between the main gearbox and the fuselage 
For the sake of clarity, the different kinematic joints are also described in the joints graph Fig. 5.

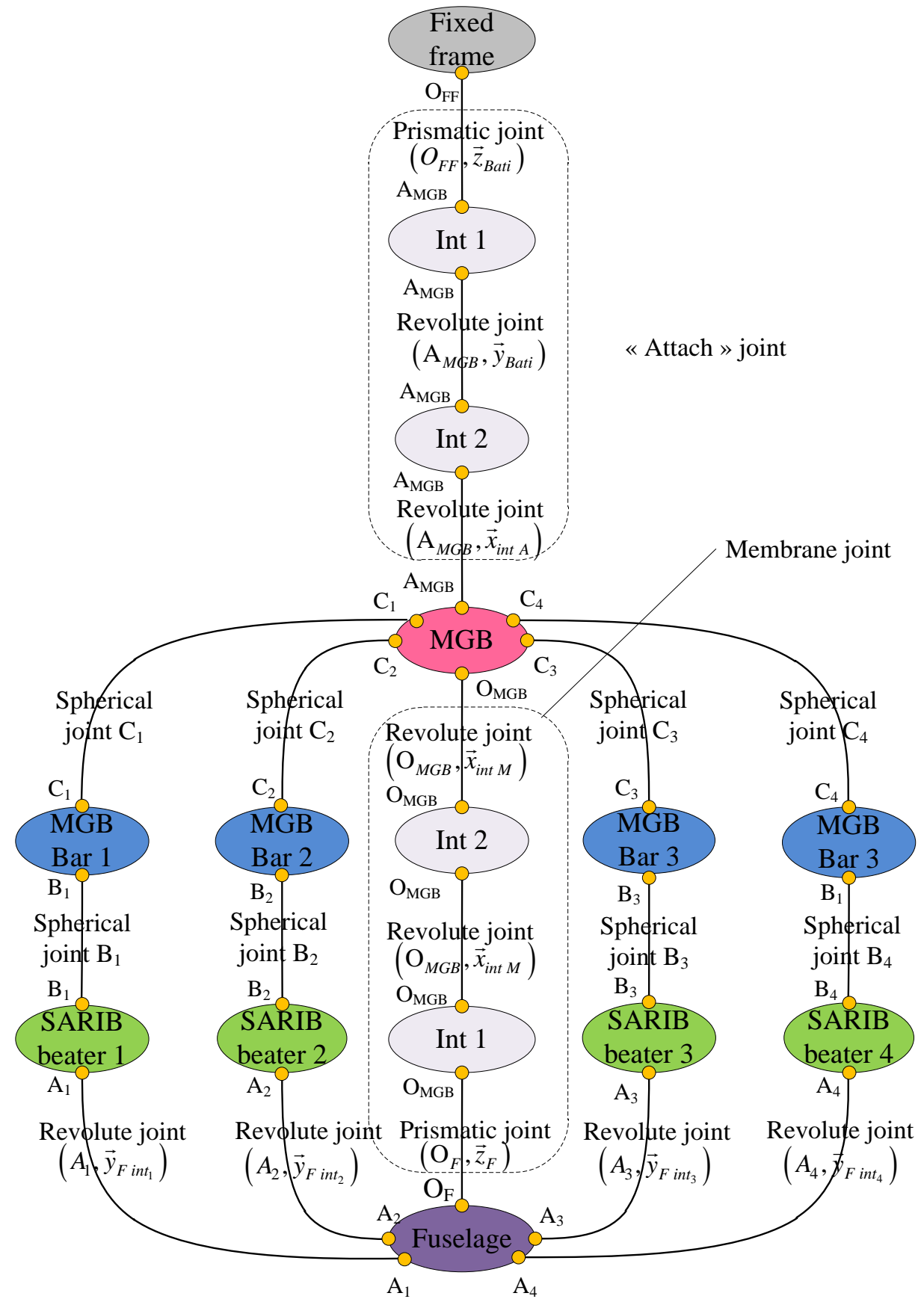

Fig. 5 - Joints graph of the 3D SARIB passive suspensions

The MGB is suspended by a joint called "attach” to the fixed frame. This joint consists of a universal joint and a prismatic joint. The weight of the system (mainly the weight of the MGB and the fuselage) is taken up by a tension spring at the prismatic joint of this attach. The spring is dimensioned such that the natural frequency of the mass / spring system is small enough and distant from the excitation frequency applied to the MGB.

The structure of the suspension consists of four identical legs and a central membrane. Each leg consists of SARIB beaters and a MGB Bar connected by a spherical joint. The upper ends of these legs are connected to the MGB with spherical joints and the lower ends of these legs are connected to the fuselage through revolute joints. The revolute joints between SARIB beaters and the fuselage have a torsion spring dimensioned such that the antiresonance frequency in the efforts transmitted to the fuselage is positioned on the rotor excitation frequency while taking up enough the effort to lift the helicopter with a small displacement between the MGB and fuselage. 
Given the physical phenomena observed, the main membrane between the MGB and the fuselage is modeled by two revolute joints with orthogonal axes (also called universal joint) and a prismatic joint in serial. The flexibilities of the membrane in pumping, roll, and pitch are modeled by the degrees of freedom of these joints combined with stiffness. A torsion spring with low stiffness at each revolute joint of the universal joint and a linear spring, also with low stiffness along the z-axis will model the filtering carried out by the membrane. The rigidities of the membrane are modeled by rigid joints or, in other words, by a lack of degree of freedom around or along the movements considered.

These bodies are assumed to be rigid. The intermediate parts (called Int1 and Int2) are supposed with negligible masses. As previously mentioned, absolute coordinates have been chosen for modularity reasons. Some local moving reference frames are attached to these bodies:

$R_{F F}=\left(O_{F F}, \vec{x}_{F F}, \vec{y}_{F F}, \vec{z}_{F F}\right)$ attached to the fixed frame,

$R_{M G B}=\left(G_{M G B}, \vec{x}_{M G B}, \vec{y}_{M G B}, \vec{z}_{M G B}\right)$ attached to the MGB,

$R_{S B}=\left(G_{S B}, \vec{x}_{S B}, \vec{y}_{S B}, \vec{z}_{S B}\right)$ attached to the SARIB Beaters,

$R_{M B}=\left(G_{M B}, \vec{x}_{M B}, \vec{y}_{M B}, \vec{z}_{M B}\right)$ attached to the MGB Bar,

$R_{F}=\left(G_{F}, \vec{x}_{F}, \vec{y}_{F}, \vec{z}_{F}\right)$ attached to the fuselage and $R_{F \text { int }_{i}}=\left(A_{i}, \vec{x}_{F \text { int }}, \vec{y}_{F \text { int }_{i}}, \vec{z}_{F \text { inti }}\right)$ also attached to fuselage so as to facilitate the definition of the axis of the revolute joints.

\subsection{Modeling assumptions of the suspension environment}

As previously mentioned in section 1, the action of the rotor on the MGB in the experimental setup is approximated by a sinusoidal excitation with a frequency $b \Omega$.

The external mechanical actions applied to the MGB are the forces applied by the vibrating shakers. The description of the experimental setup shall be specified in Section 5.2 of this paper. These excitations will be applied along or around the joints of the "attach" joint between the fixed frame and the MGB. They allow the MGB to be subjected to pumping, pitch and roll excitations. These mechanical actions will only consist of a dynamic component to analyse the vibration behaviour of the suspension.

For the pumping excitation, the wrench applied by the actuator at the mobility of the prismatic joint is:

$$
\tau(\text { actuator along vertical axis } \rightarrow \text { prismatic joint })=\left\{\begin{array}{c}
f(t) \vec{z}_{\text {Bati }} \\
\overrightarrow{0}
\end{array}\right\} \text { avec } f(t)=F \times g(t)
$$

For roll excitation, the wrench applied by the actuator at the mobility of the revolute joint around roll axis is:

$$
\tau(\text { Actuator around roll axis } \rightarrow \text { roll revolute joint })=\left\{\begin{array}{c}
\overrightarrow{0} \\
m_{r}(t) \vec{y}_{\text {Bâti }}
\end{array}\right\} \text { avec } m_{r}(t)=M \times g(t)
$$

For pitch excitation, the wrench applied by the actuator at the mobility of the revolute joint around pitch axis is:

$$
\tau(\text { actuator around pitch axis } \rightarrow \text { pitch revolute joint })=\left\{\begin{array}{c}
\overrightarrow{0} \\
m_{p}(t) \vec{x}_{\text {int } A}
\end{array}\right\} \text { avec } \quad m_{p}(t)=M \times g(t)
$$

Different types of excitation are used by modulating the amplitude of each excitation by a dimensionless function $\mathrm{g}(\mathrm{t})$ : constant, sinus type or swept sine. The constant excitation permits to ensure that the equilibrium position of the system under its own weight is physically acceptable. The sine excitation permits to get more accurate frequencies of the anti-resonance frequencies.

The swept sine excitation is used to analyze the frequency behaviour of the system including resonances and anti-resonances frequencies.

For the swept sine excitation, a modulation function was constructed, as shown in four parts:

- within [0, $\left.\mathrm{t}_{1}\right]$, a progressive increase to a sinusoidal excitation at a frequency of $f_{\text {start }}$ de $5 \mathrm{~Hz}$ is carried out with a linear amplitude variation,

$$
\left\{\begin{array}{c}
\forall t \in\left[0, \frac{t_{1}}{2}\right], \quad g(t)=\left(4 \frac{t^{2}}{t_{1}^{2} 2}\right) \sin \left(\omega_{\text {start }} t\right) \\
\forall t \in\left[\frac{t_{1}}{2}, t_{1}\right], \quad g(t)=\left(-\frac{2}{t_{1}^{2}}\left(t-\frac{t_{1}}{2}\right)^{2}+\frac{2}{t_{1}}\left(t-\frac{t_{1}}{2}\right)+\frac{1}{2}\right) \sin \left(\omega_{\text {start }} t\right)
\end{array}\right.
$$


- within $\left[\mathrm{t}_{1}, \mathrm{t}_{2}\right]$, the sine excited mode at $f_{\text {start }}$ is preserved the necessary time so that the transient mode disappears and there is only permanent regime,

$$
\forall t \in\left[t_{1}, t_{2}\right], \quad g(t)=\sin \left(\omega_{\text {start }} t\right)
$$

- within $\left[\mathrm{t}_{2}, \mathrm{t}_{3}\right]$, a linear swept sine is used with a sweep frequency from $f_{\text {start }}(5 \mathrm{~Hz})$ to $f_{\text {end }}(25 \mathrm{~Hz})$. The expression of the chirp signal is given in [33] and recalled below :

$$
\forall t \in\left[t_{2}, t_{3}\right], g(t)=\sin \left(\left(\omega_{\text {start }}+\frac{\Delta \omega}{2 \Delta T}\left(t-t_{2}\right)\right) \times\left(t-t_{2}\right)\right)
$$

With $\Delta \omega=\omega_{\text {end }}-\omega_{\text {start }}$ and $\Delta T=t_{3}-t_{2}$

- within $\left[\mathrm{t}_{3},+\infty\right]$, the sine excited mode at $f_{\text {end }}=\frac{\omega_{\text {end }}}{2 \pi}(25 \mathrm{~Hz})$ is kept.

$$
\forall t \in\left[t_{3},+\infty\right], \quad g(t)=\sin \left(\omega_{\text {end }} t\right)
$$

For the conducted simulations, the time intervals were defined with the numerical following values: $t_{1}=3 \mathrm{~s}, \mathrm{t}_{2}=5 \mathrm{~s}$ and $\mathrm{t}_{3}=25 \mathrm{~s}$.

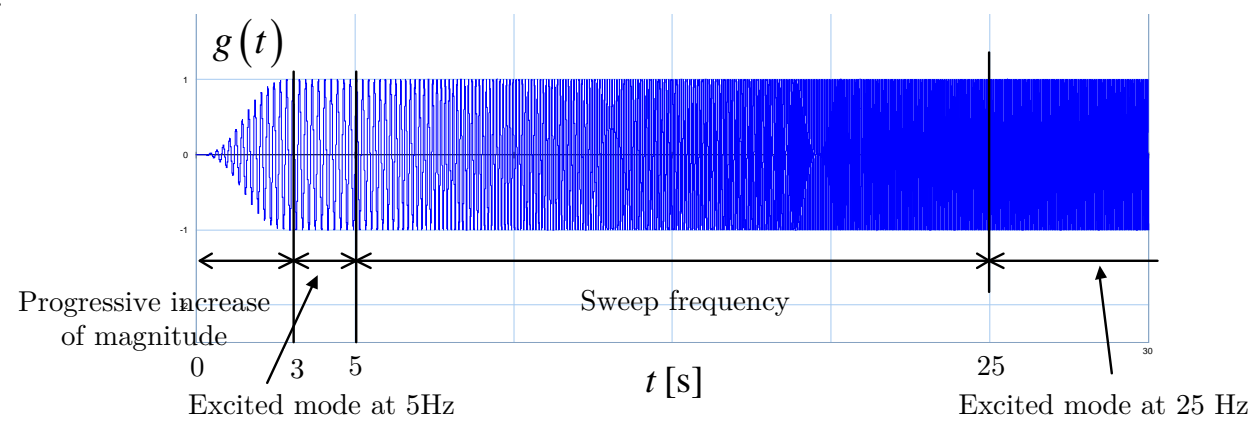

Fig. 6 - Modulation function of the excitation $g(t)$

\subsection{Construction of the bond graph model of the MGB-Fuselage joint}

\subsubsection{Components modeling}

The components modelling (rigid bodies and kinematic joints) of the system will be now be presented.

\subsubsection{Rigid bodies}

\section{A reminder of the general rigid body modelling}

Let us remember the architecture of a rigid body multibond graph model based on [5], [8], [25], [34].

This bond graph architecture is based on the Newton-Euler equations with the inertia matrix (modeled with a multiport energy store element $\left[\mathbf{I}_{S_{i}, G_{i}}\right]$ in the upper part) associated with gyroscopic terms respectively (modeled with a multiport gyrator element also called Eulerian Junction Structure about mass-center of body i expressed in its frame $\left[\mathbf{E J S}_{G_{i}}\right]_{i}$ and the mass matrix modeled with a multiport energy store element $\left[\mathbf{m}_{i}\right]_{0}$ in the lower part).

The upper part of the bond graph represents the rotational dynamic part expressed in the body frame while the lower part is for the translational dynamic part expressed in the inertial reference frame (or Galilean frame). The two corresponding 1 -junctions arrays correspond respectively to the angular velocity vector of body i $\vec{\Omega}(i / 0)^{i}$ and the translational velocity vector of the center of mass of body i $\vec{V}\left(G_{i} / R_{0}\right)^{0}$ expressed in these two coordinate frames.

The central part of the MBG describes the kinematic relations between the velocities of the two points of the body i $\left(\vec{V}\left(M_{j} / R_{0}\right)^{i}\right.$ and $\left.\vec{V}\left(M_{k} / R_{0}\right)^{0}\right)$ and the velocity of the center of mass $\vec{V}\left(G_{i} / R_{0}\right)^{i}$ resulting from the formula of the rigid body. 

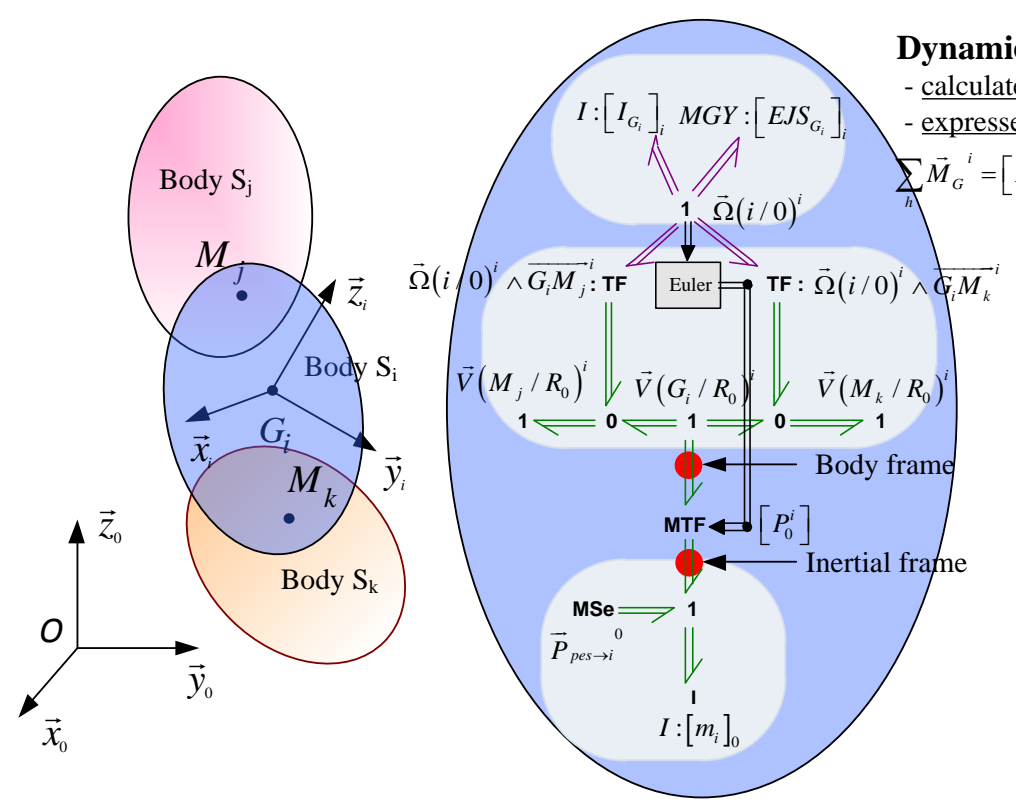

Dynamic moment theorem

calculated in $\mathrm{G}$ relative to the inertial frame expressed in the body frame

$\vec{M}_{G}{ }^{i}=\left[I_{G_{i}}\right]^{i}\left[\frac{d}{d t}\left(\vec{\Omega}(i / 0)^{i}\right)_{0}\right]^{i}+\vec{\Omega}(i / 0)^{i} \wedge\left(\left[I_{G_{i}}\right]^{i} \vec{\Omega}(i / 0)^{i}\right)$

Kinematic relations

$\vec{V}\left(M_{j} / R_{0}\right)^{0}=\vec{V}\left(G_{i} / R_{0}\right)^{0}+\vec{\Omega}\left(S_{i} / 0\right)^{0} \wedge{\overrightarrow{G_{i} M_{j}}}^{0}$

$\vec{V}\left(M_{k} / R_{0}\right)^{0}=\vec{V}\left(G_{i} / R_{0}\right)^{0}+\vec{\Omega}\left(S_{i} / 0\right)^{0} \wedge{\overrightarrow{G_{i} M_{k}}}^{0}$

\section{Frame transformation}

\left.${\overline{V\left(G_{i} / R_{0}\right.}}^{0}=P_{0}^{i} \cdot \overrightarrow{V\left(G_{i} / R_{0}\right.}\right)^{i}$

\section{Force dynamic theorem}

- calculated relative to the inertial frame - expressed in the inertial reference frame $\sum_{h} \vec{F}_{h \rightarrow i}{ }^{0}+\vec{P}_{\text {pes } \rightarrow i}{ }^{0}=m_{i} \frac{d}{d t}\left(\vec{V}\left(G_{i} / R_{0}\right)^{0}\right)_{0}$

Fig. 7 - Bond graph model of the rigid body

As the translational dynamic is expressed in the inertial reference frame, a modulated transformation element (MTF) between $\vec{V}\left(G_{i} / R_{0}\right)^{i}$ and $\vec{V}\left(G_{i} / R_{0}\right)^{0}$ permits the coordinate transformation between the body frame and the inertial frame. The rotation matrix can be calculated from Euler angles. In this paper, the XYZ Cardan angles have been employed. The angular velocity components of the considered body expressed in the body frame (called the pseudo-velocities or Euler angles rates of changes) are used to determine the body's orientation and the corresponding coordinate transformation matrix. This classical process is reminded in Fig. 8. It should be noted that the initial conditions used for the integration of time derivatives of the Euler angles must be consistent in regards to the kinematic constraints.

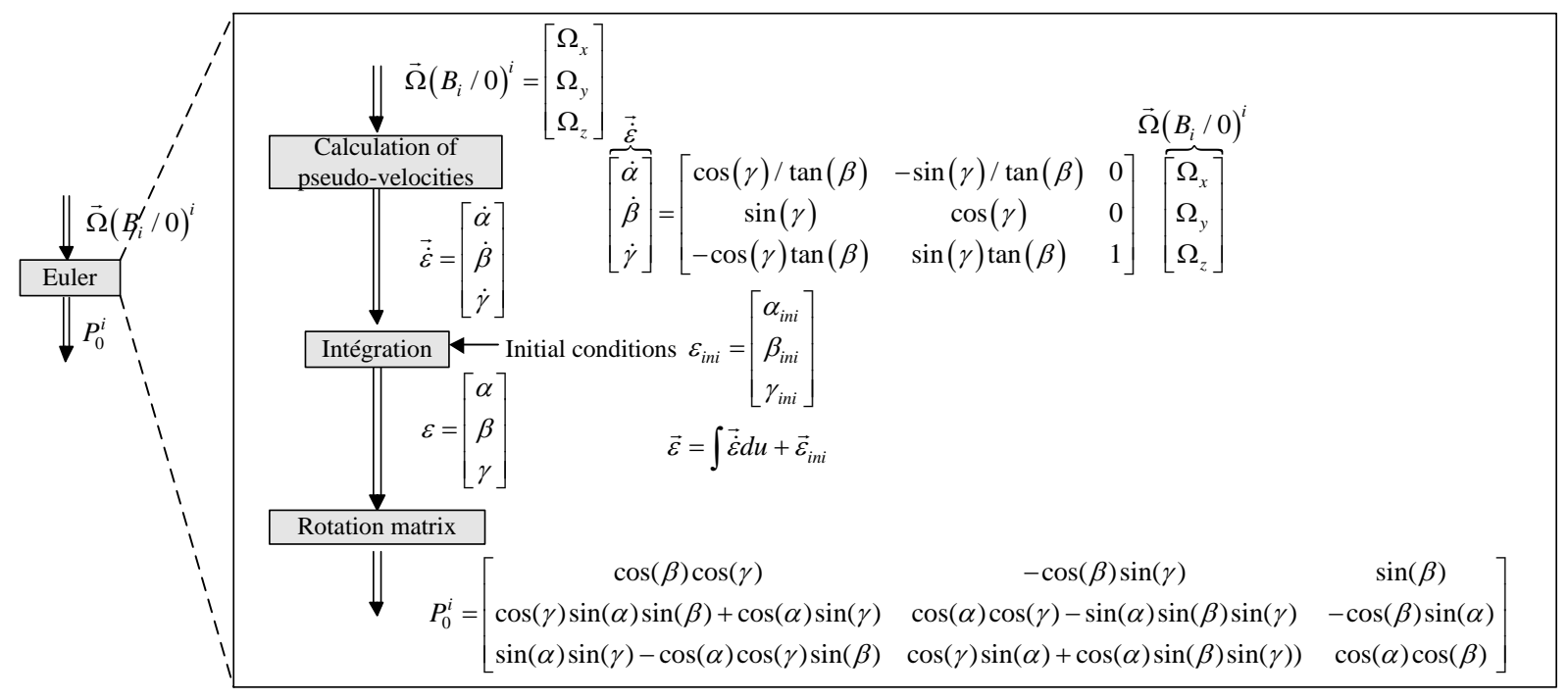

Fig. 8 - Calculation of the Euler angles and rotation matrix from the angular velocity

\section{The MGB}

The MBG representation of the construction is given in Fig. 9. The bond graph representation shows as many branches in the structure junctions as kinematic joints for the determination of the velocities of corresponding points. From the linear velocity of the center of mass $\mathrm{G}_{M G B}$ and the instant rotation velocity $\vec{\Omega}$ (MGB / Fixed frame) , the linear velocity of the point $\mathrm{O}_{\mathrm{MGB}}$, the linear velocity of $\mathrm{A}_{\mathrm{MGB}}$ point of the MGB and the linear velocities $\mathrm{Ci}$ point at the ball joints between BTP and BTP bars are calculated. 


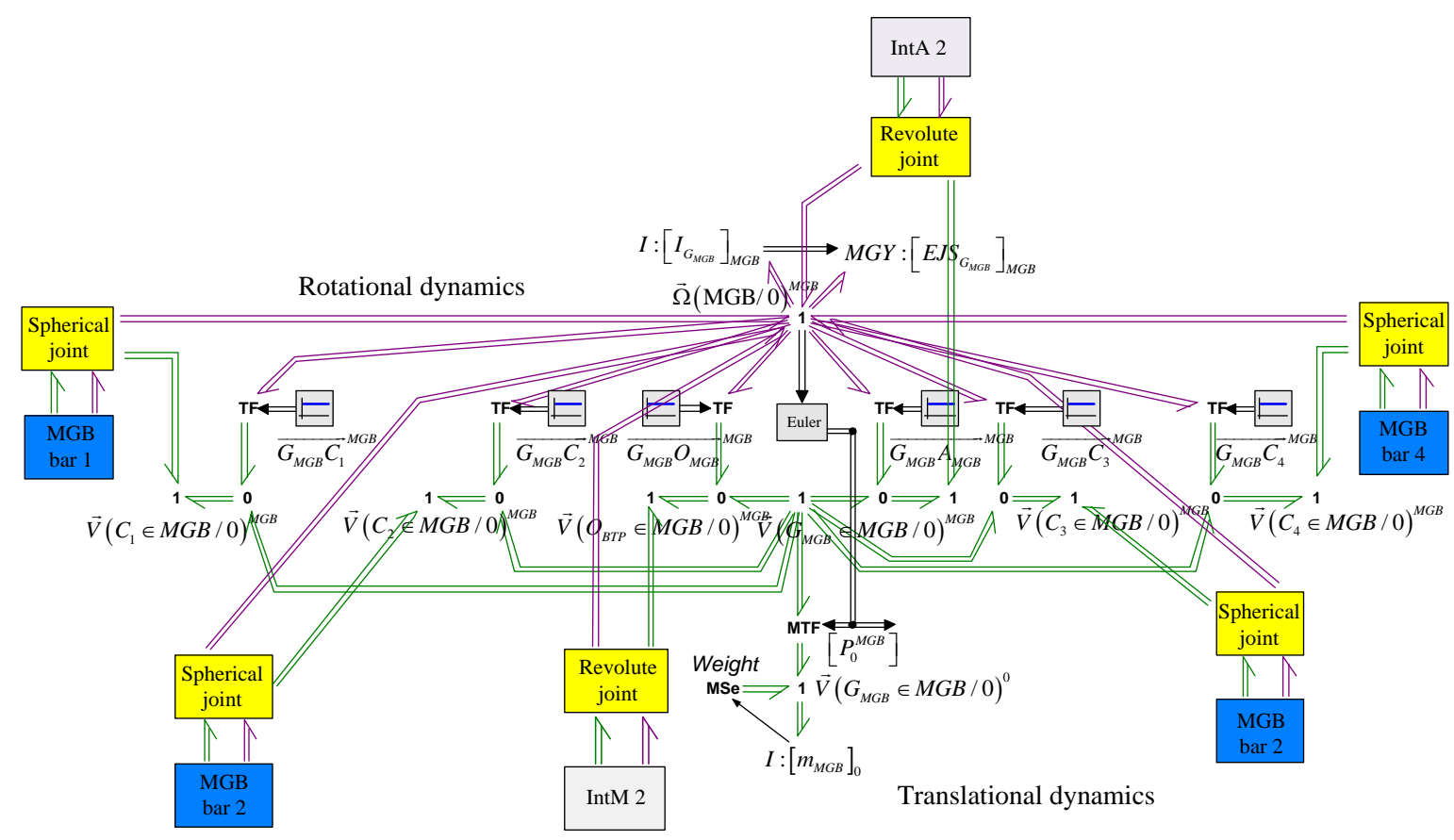

Fig. 9 - Bond graph modeling of the MGB with its environment

\section{The fuselage}

With a similar approach, the bond graph modelling of the fuselage is given in Fig. 10.

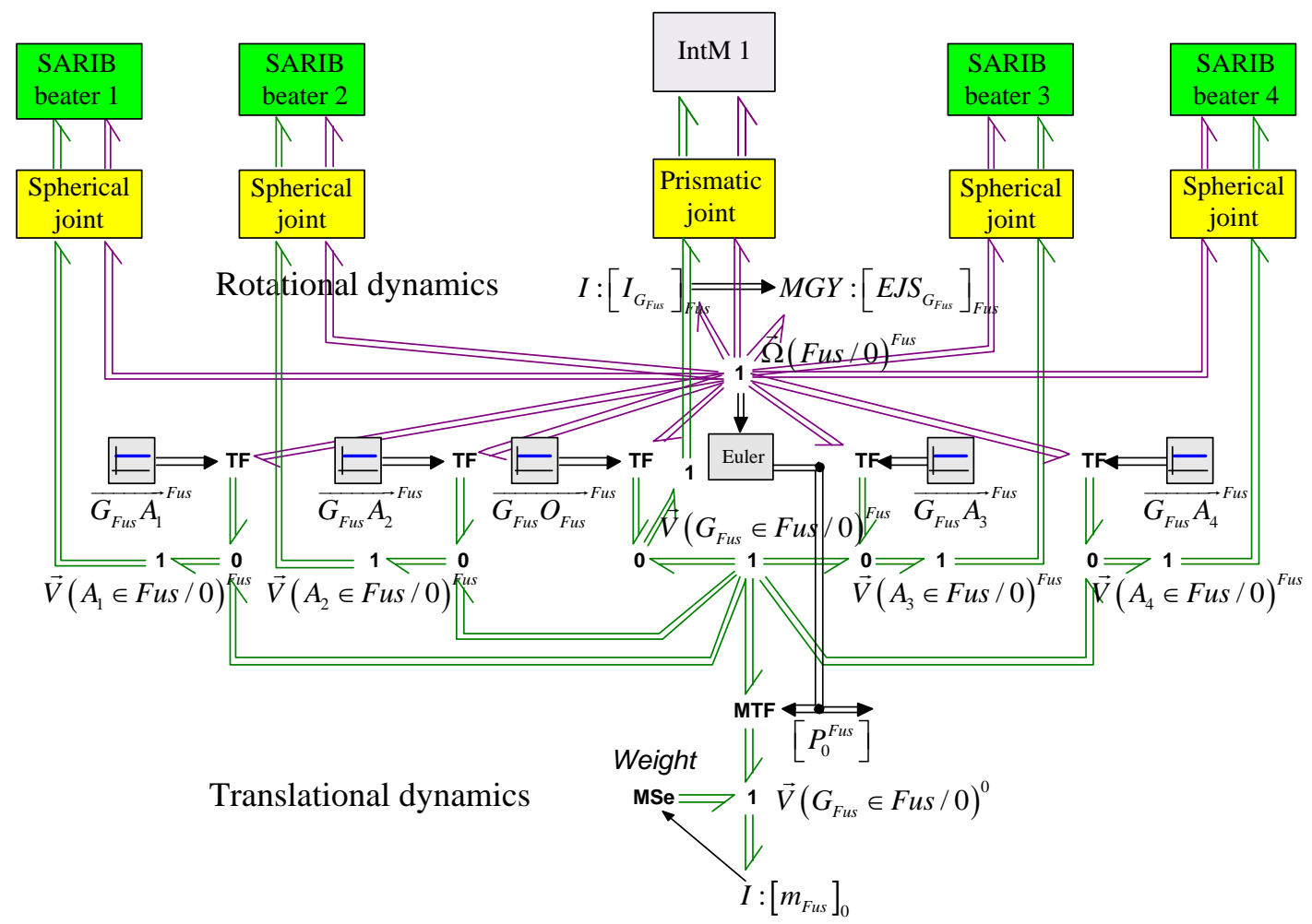

Fig. 10 - Bond graph model of the fuselage with its environment 


\section{The SARIB beaters}

The bond graph model of a SARIB beater kinematically linked to the fuselage and the MGB bars is given in Fig. 11.

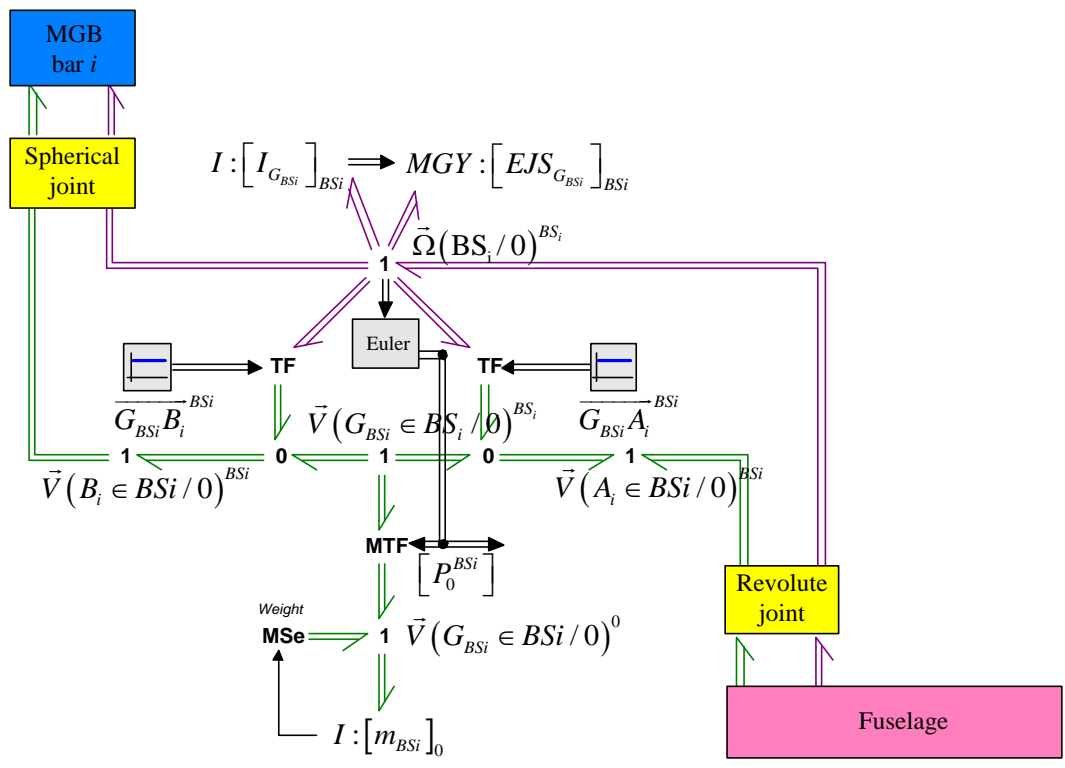

Fig. 11 - Bond graph model of a SARIB beater $i$ kinematically linked to its environment

\section{The MGB bars}

The bond graph model of a MGB bar beater kinematically linked to the MGB and a SARIB bar is given in Fig. 12.

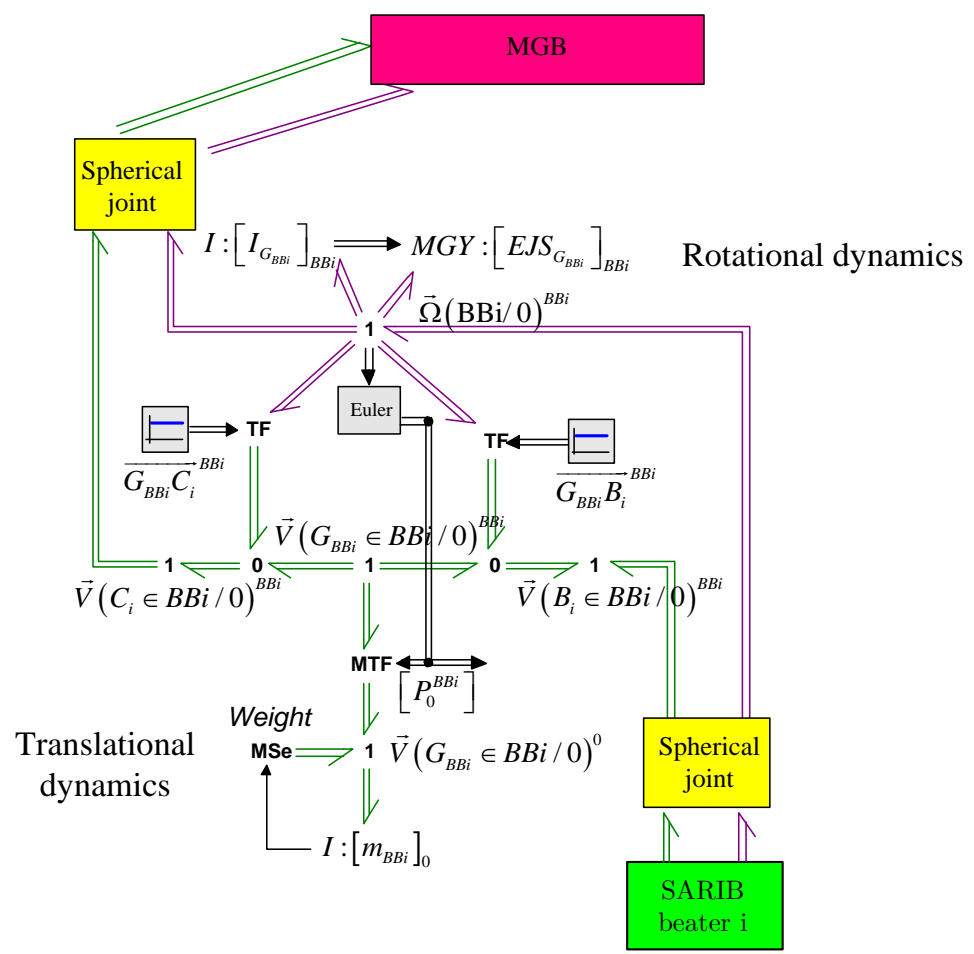

Fig. 12 - Bond graph model of MGB bar $i$ kinematically linked to its environment 


\subsubsection{Kinematic joints}

The joint modelling will now be detailed. The singular perturbation method is here implemented by the addition of parasitic elements which were presented in the previous section. The joint models permit the expression of the constraints that are introduced when rigid bodies are connected. As the bond graph model of the rigid body, the joint models have been built in a modular way in the sense that they have links with rigid bodies and their modelling does not change when the whole model of the system is assembled.

\section{The revolute joints}

Eight revolute joints are present in the system: two for the universal joint in the attach joint between the fixed frame and the MGB, two for the universal joint in the membrane between the MGB and the fuselage, and four between each SARIB beaters and the fuselage. The bond graph modelling between the SARIB beaters and the fuselage is given in Fig. 13. The bond graph models of the other revolute joints are designed in a similar manner.

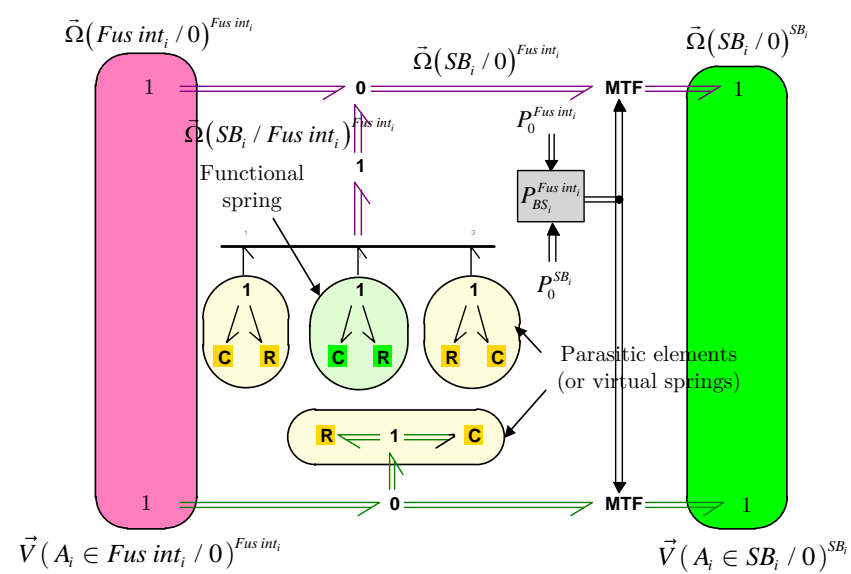

Fig. 13 - Bond graph model of the revolute joint between the SARIB beaters and the fuselage

The upper part of this joint's model corresponds to the angular velocities. The lower part of this joint's model corresponds to the translational velocities. The R/C elements in this model are functionally different. On the one hand, the R/C elements corresponding to the stiffness and damping around the y axis (revolute joint's axis) model the behaviour of the torsional spring. On the other hand, the R/C elements with high stiffness and some damping around the other axes model the virtual springs since there are no physical springs in these directions. They permit to block the degree of freedom along and around these axes and make the numerical simulation possible (as explained in section 3).

\section{The spherical joints}

Eight spherical joints are present in the system: four between the SARIB beaters and the MGB bars and also four between the MGB bars and the MGB. The bond graph modelling of the spherical joint between the SARIB beater and a MGB Bar is described in Fig. 14. The latter shows the blocking of the translational degree of freedom in which the relative translational velocities are close to zero thanks to the virtual springs. The other spherical joints are built in the same manner.

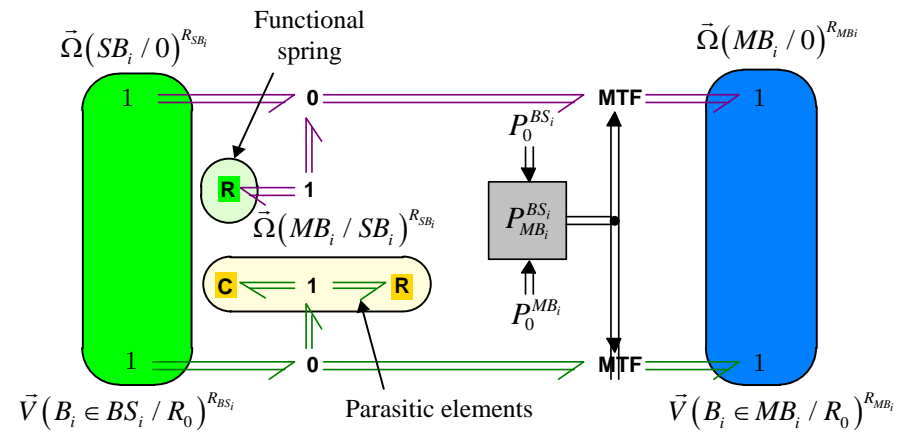

Fig. 14 - Bond graph model of the spherical joint between a MGB bar i and a SARIB beater i 


\section{The prismatic joints}

The bond graph model of the prismatic joint between the MGB and an intermediate body is given in Fig. 15.

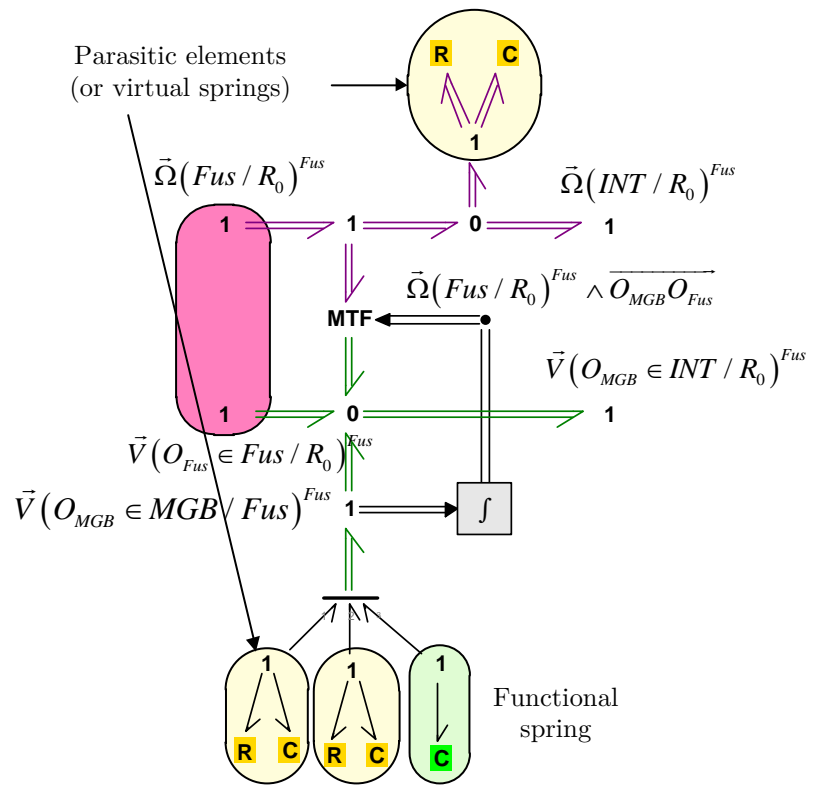

Fig. 15 - Bond graph model of the prismatic joint between the MGB and a intermediate body

\subsubsection{Excitation models}

The mechanical actions developed by the actuators are modelled by an effort source connected to the junctions $\mathbf{1}$ which are free in the attach joint. The example of the implementation of an excitation by a swept sine at the pitch joint is shown in Fig. 16.

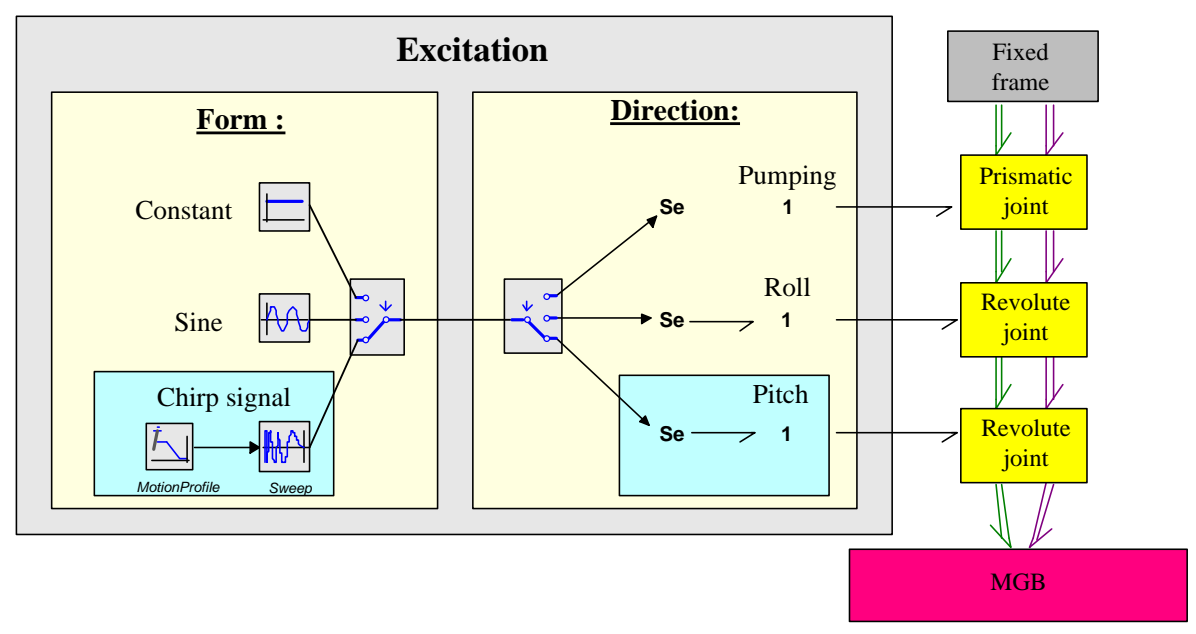

Fig. 16 - Bond graph model of the actuators of the excitation

Depending on the selected excitation direction (pumping, roll or pitch), this source will be respectively connected either to the free junction of the prismatic joint, or the revolute joints around the roll or pitch axis. Three choices of excitation forms may also be selected: constant for a natural mode excitation (if this constant is zero) or a static study, sinusoidal or swept sine for excited modes.

The practical realization of these actuators will be conducted using vibration shakers as we will detail in the experimental validation section.

\subsubsection{Assembly}


These rigid bodies and joints models, as described above, are then connected together according to the architecture defined in the kinematic diagram. The bond graph model of the 3D MGB-fuselage suspension is given below in Fig. 17. As expected, the structural aspect of the model is explicit in so far as the structure of the model is similar to the joints graph of the system.

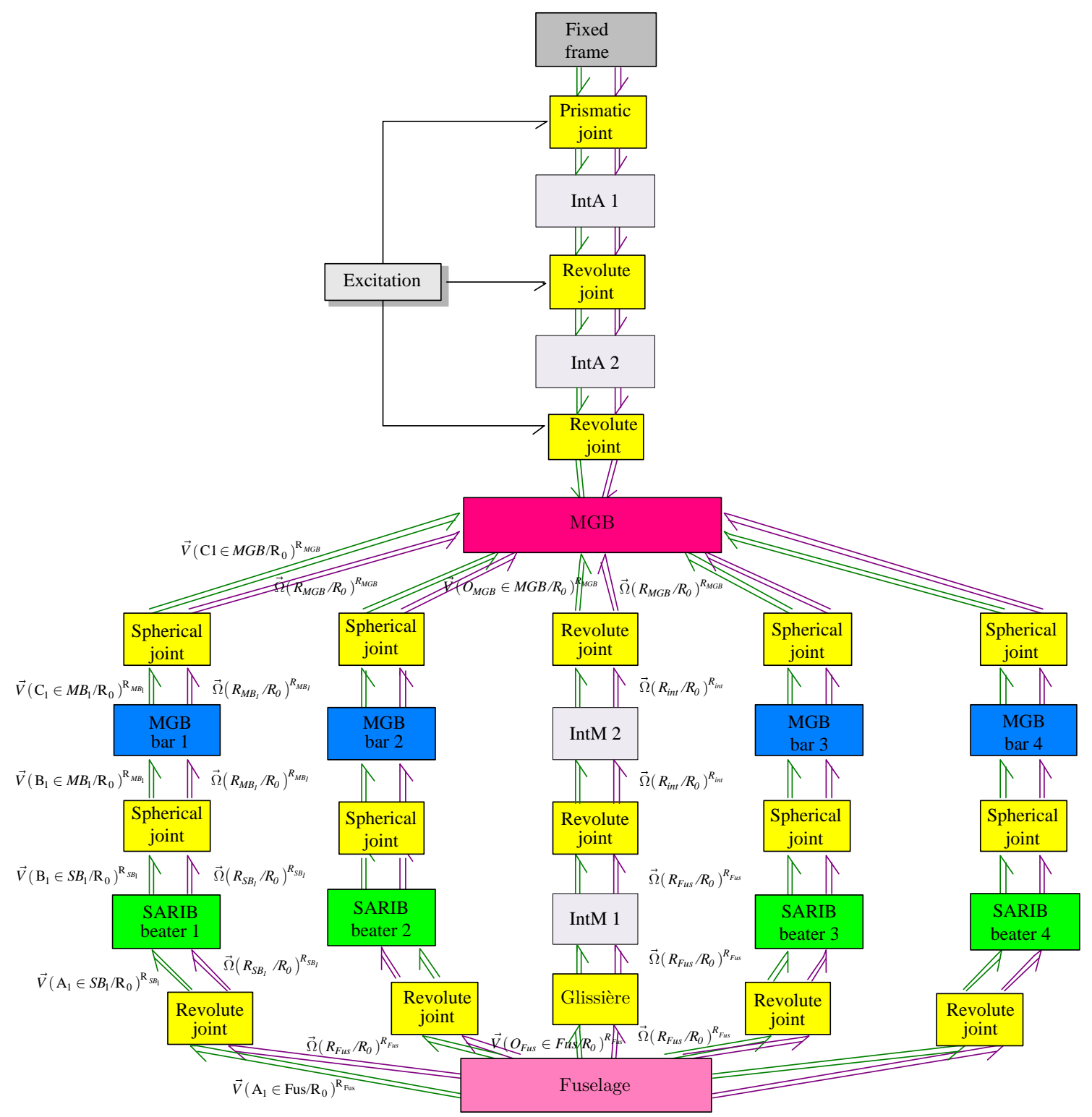

Fig. 17 Bond graph model of the passive MGB-fuselage suspension

\subsubsection{Simulation protocol}

\section{Getting equations}

The step of generating the mechanical equations is fully automated and transparent to the user using the 20-sim software. In this step, the solver reads data corresponding to the bond graph model and builds a mathematical problem: the equations of the system.

\section{Resolution of the equations}

The used bond graph software (20-sim) then solves the equations. With the method of singular perturbation, this step resolution can be performed simply using classical integration schemes for solving differential equations ODE solver such as Runge Kutta 4 (RK4). However, the integration scheme that has been used is the Backward 
Differentiation Formula (BDF). It was preferred as it allows a simulation of a stiff problem which is much faster than explicit solvers (like RK4).

\section{Post-processing}

From the mathematical solution, the solver computes and communicates the results requested by the user. 20sim allows the user to evaluate and easily plot any of the physical quantities involved in the bond graph model of the system. In addition, graphs can be exported to various types of image-formats or data with .csv or .xls file. The data exportation allows for the comparison of results from different sources in the same graphic interface (for example Matlab).

\section{Simulation and validation of the passive suspension}

\subsection{Validation protocol}

So as to validate the suspension's model, a process based on two steps has been conducted.

The first step is a verification step by comparison of the simulation results with MapleSim software which contains a library dedicated to multibody systems.

The second step is a validation step by comparing the simulation results with those provided from the experimental setup. This step will be presented in future works since the electronic devices and the vibration equipment are not yet installed.

\subsection{Complementary description of the experimental setup}

The experimental setup was performed by maintaining the architecture of a real device (Fig. 3). The correspondence between the different mechanical elements of a helicopter and the experimental setup will be detailed in this paragraph.

To reproduce the effects of the rotor lift, the set $\{$ BTP-link-fuselage $\}$ has been suspended from the fixed frame (Fig. 3). This joint has to lift up the entire weight suspended by analogy to the static force of lift, it was performed by the use of pneumatic components. They were designed so that the natural frequency induced by the overall stiffness is below $2 \mathrm{~Hz}$.

The fuselage was replaced by a rigid mass called fuselage mass (Fig. 3).

A single body has replaced the set \{rotor shaft-MGB\} and the rotation has been deleted. This single body is composed of a shaft equipped with a recessed tray (Fig 18).

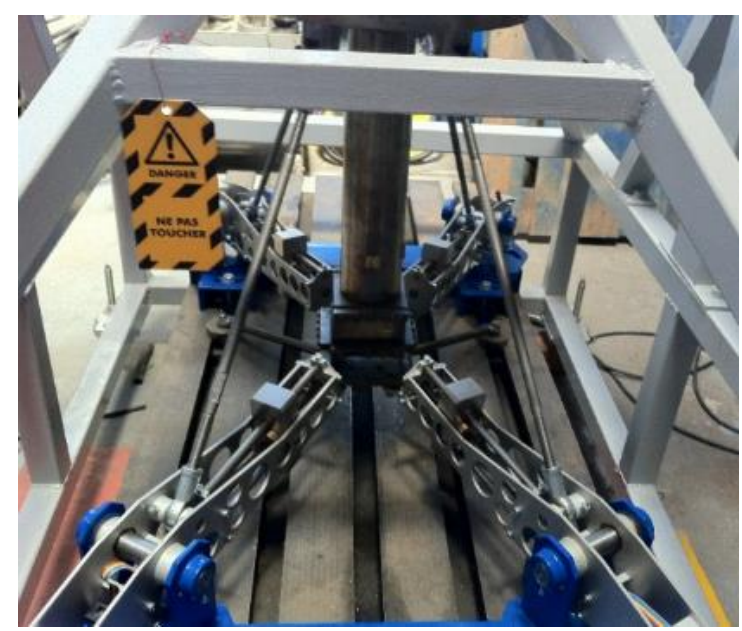

Fig 18 - Position of the fixtures to the fuselage 
The overall joint between the fuselage mass and the system equivalent to the set \{rotor shaft-MGB has four bars, four semi-active SARIB beaters and a system representing the usually existing membrane on the helicopter.

The MGB bars consist of threaded rods that have a spherical joint without backlash at each end.

Each SARIB beater is linked by a revolute joint to the fuselage, which are themselves clamped to the fuselage mass as shown in Fig 18. Each SARIB beater is fitted with a moving mass (Fig.19) connected with a prismatic joint along the SARIB beater. The translational movement is controlled by means of a screw-nut system and a DC motor. It should be noted that, in this section, the moving masses are fixed on the SARIB beaters.

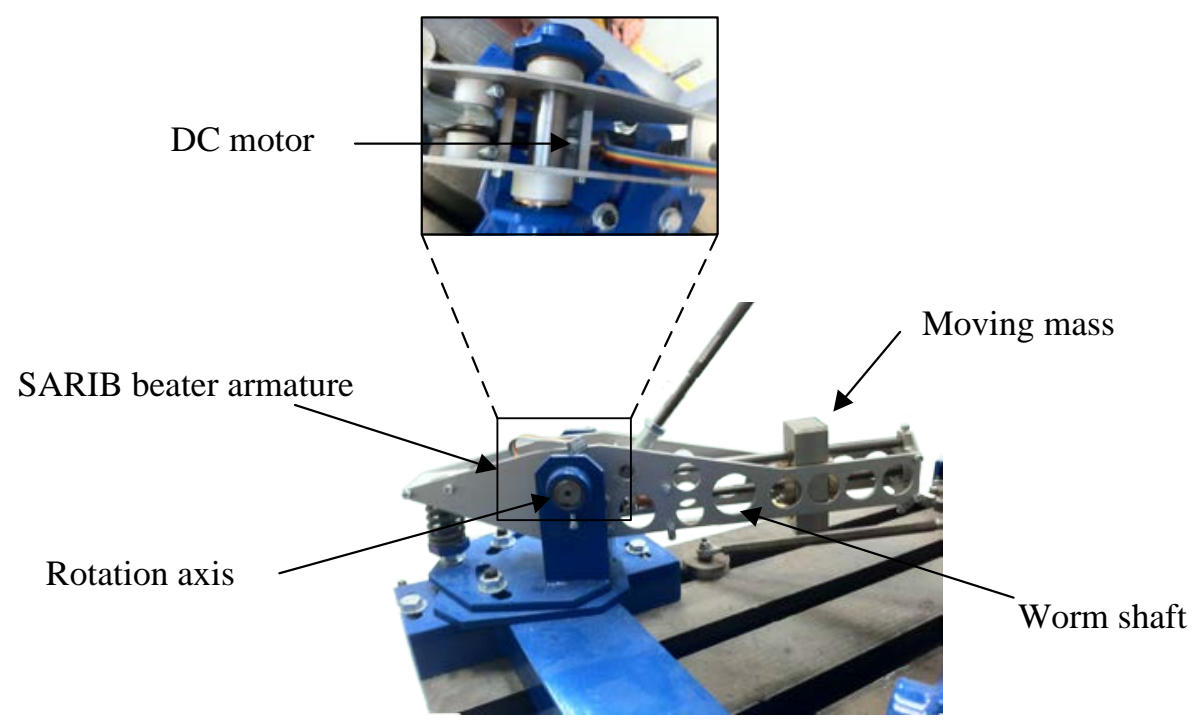

Fig.19 - Revolute joint between a SARIB beater and the fuselage

\subsection{Use of MapleSim for BG model verification}

The simulation parameters used for both the bond graph simulation and Maplesim simulation are summarized in the following table.

Table 1. Simulation comparison

\begin{tabular}{lll}
\hline \hline Software & MapleSim & Bond graph conducted with 20-sim \\
\hline \hline Solver & Rosenbrock (stiff) & Backward Differentiation Formula (BDF) \\
\hline Method & Linear graph theory & Singular perturbation \\
\hline Number of coordinates & 84 (14 bodies) & 84 (14 bodies) \\
\hline \multirow{3}{*}{ Number of constraints } & $\begin{array}{l}74 \\
\text { (8 spherical joints, 8 revolute joints, } \\
\text { 2 prismatic joints) }\end{array}$ & 0 \\
\hline DoF & $10(6+4)$ & 84 \\
\hline
\end{tabular}

\subsection{Comparison between simulation numerical results and experimental result}

The vibration analysis of the system is mainly evaluated by analyzing the acceleration of the fuselage points and forces transmitted from the MGB to the fuselage at the SARIB beater/ fuselage joint. Simulation results with different types of excitation (pumping, roll, pitch) are the following and will permit to analyze the dynamic behavior of the suspension. The results presented were compared with a multibody software MapleSim.

\subsubsection{Dynamic behavior with pumping excitation}

\subsubsection{Acceleration of the point $\mathrm{O}_{\mathrm{F}}$ of the fuselage}


The point $\mathrm{O}_{\mathrm{F}}$ is defined as the intersection of the MGB's axis and the upper plane of the fuselage. It is a central point on the fuselage that can be measured.

The vertical component of the acceleration of this point is given in Fig. 20

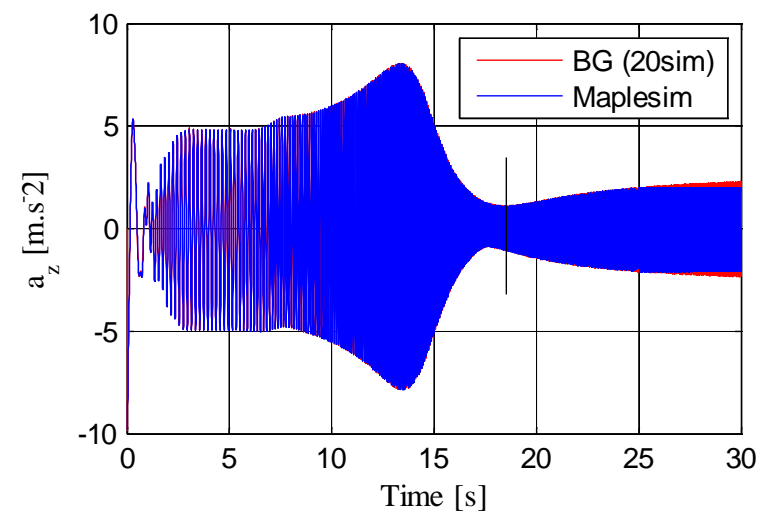

Fig. 20 - Vertical component of the acceleration of the point $\mathrm{O}_{\mathrm{F}}$ for a pumping excitation

An anti-resonance frequency is observed at $18.5 \mathrm{~Hz}$.

The curve obtained with Maplesim is very close to the curve obtained with the simulation of the bond graph model with 20-sim.

\subsubsection{Forces transmitted to the fuselage}

The forces transmitted to the fuselage at the revolute joints between the SARIB beaters and the fuselage expressed in the intermediate pins fuselage were determined as shown in Fig. 20.

As shown in the above figures, the curves of the vertical forces transmitted at the revolute joints are logically similar to the curve of the acceleration of the point $\mathrm{O}_{\mathrm{F}}$. Through the action of inertial forces, the transmission forces of the MGB to the fuselage are reduced at a certain frequency called antiresonance frequency. They present an antiresonance at about $18.5 \mathrm{~Hz}$. SARIB beaters thus play their roles.

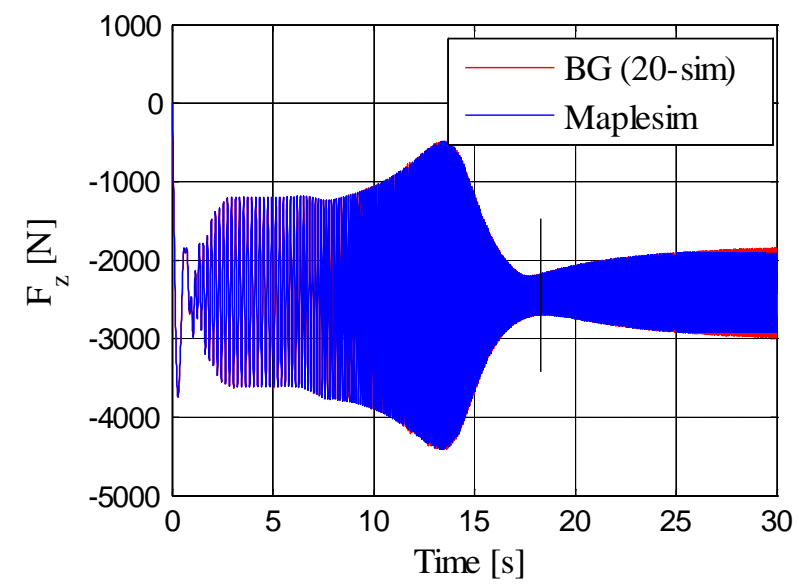

Fig. 21 - Vertical force transmitted to the fuselage at the revolute joint A1 for a pumping excitation

We can observe in Fig. 22 that the anti-resonance phenomenon observed in the force along x-axis in the intermediate fuselage frames does not occur at the same frequency as the one which had been observed for the transmission of vertical forces to the fuselage (for reminding around $18.5 \mathrm{~Hz}$ ). The frequency of anti-resonance is around $16.3 \mathrm{~Hz}$. The designer will have to monitor the amplitude of the component along $\mathrm{x}$-axis of these forces which are not minimal at the anti-resonant frequency for the vertical forces transmitted to the fuselage. 


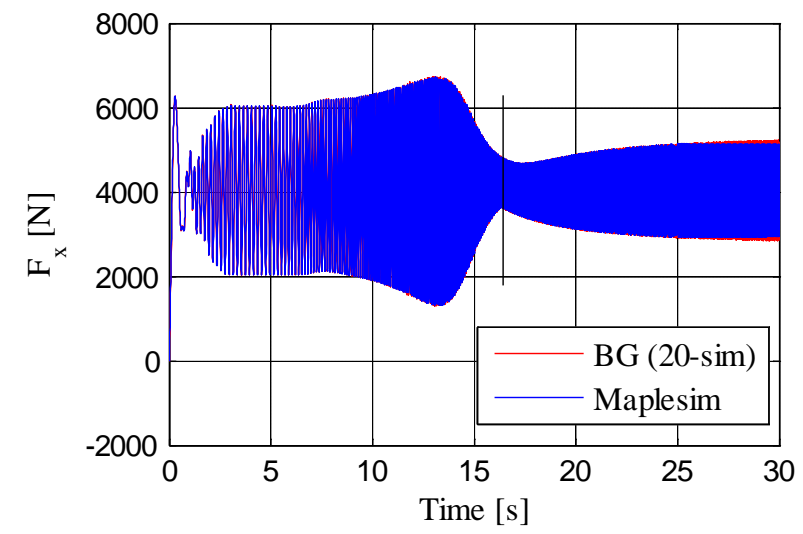

Fig. 22 - Force along $\mathrm{x}$ axis in the intermediate fuselage frame at the revolute joint A1 for a pumping excitation

\subsubsection{Dynamic behavior with roll excitation}

The vertical force transmitted to the fuselage at the revolute joint A1 between the SARIB beaters and the fuselage expressed in the intermediate fuselage frames was determined as shown in Fig. 23. As previously, an antiresonance phenomenon is observed at the frequency of $18.5 \mathrm{~Hz}$.

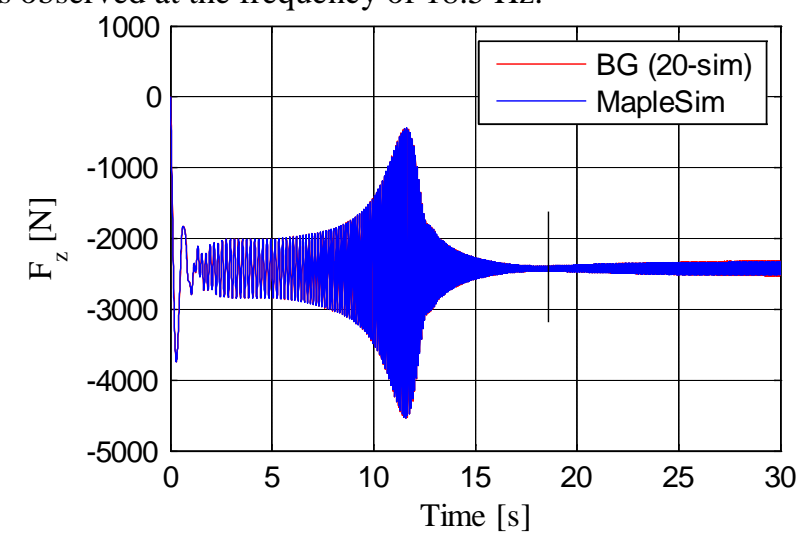

Fig. 23 - Vertical force at the revolute joint A1 for a roll excitation

In Fig. 24, we can notice the phase shift between the vertical force at the revolute joint A1 and the revolute joint A2 when the MGB is submitted to a roll excitation.

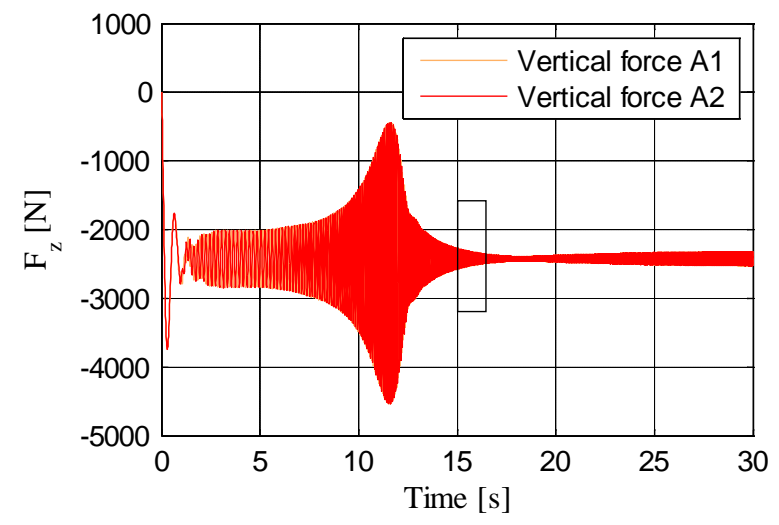

(a)

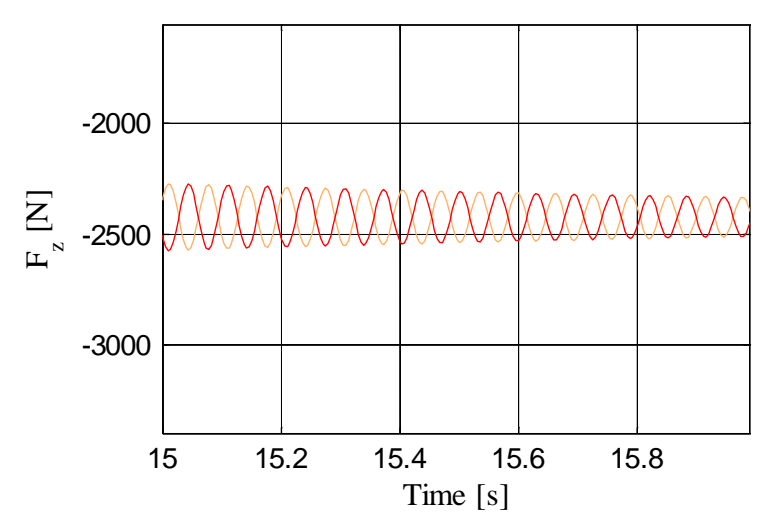

(b)

Fig. 24 - (a) Vertical forces at the revolute joints A1 and A2 with a roll excitation, (b) zoom

\subsubsection{Dynamic behavior with pitch excitation}

Similar results are observed for a pitch excitation but are not presented for the sake of concision. 


\section{Modeling and simulation of the semi-active suspension}

In this part, the multiphysic properties of the bond graph approach will be illustrated by the addition of electrical actuators directly in the multibody system. Next, a control command structure of the mechatronic model will be proposed through the semi-active suspension. This section will thus show how structural (for the model of the mechatronic system) and functional (for the model of the command) approach can be conducted in a unique 20sim model.

\subsection{Operating description}

The objective of a semi-active suspension is to improve the reduction of vibrations despite some fluctuations of the frequency of the rotor excitation. The principle of the semi-active device is to maintain the positioning of the anti-resonant frequency of the suspension on the rotor excitation frequency. This tuning of the anti-resonant frequency can be obtained by changing the inertia of the assembly properties \{SARIB beaters + moving masses\}. More specifically, these inertial properties are altered by changing the position of the moving masses on SARIB beaters. For this purpose, the movement of the moving masses is actuated by a rotating DC motor and a screw-nut system. Contrary to an active system, the mechanical energy brought by the actuators is only used to change the system parameters (inertia of SARIB beaters). The actuators produce no effort to oppose directly to incoming efforts. Therefore, such a system is referred to as semi-active.

\subsection{Integration of the electromechanical actuators models}

The models of moving masses in prismatic joint with regard to the SARIB beaters are added to the bond graph model of the passive suspension previously built with fixed masses as shown in Fig. 25.

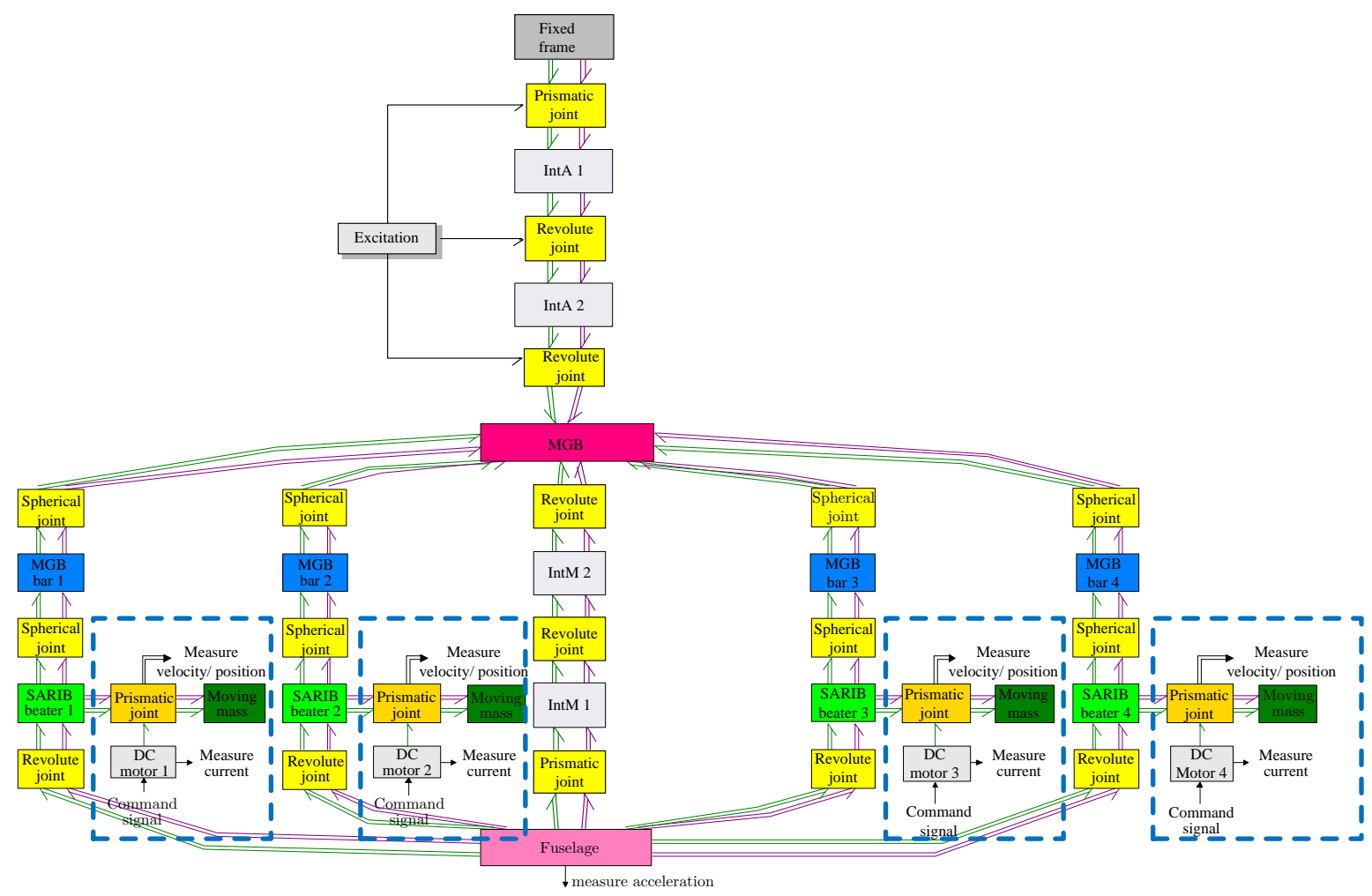

Fig. 25 - Bond graph model of the MGB-fuselage joint with moving masses (in dotted rectangles)

The model of the device \{DC motor + screw nut \} will first be presented in a model allowing the movement of a mass along an axis and then integrated into the system MGB-fuselage joint. Inspired from [5], the bond graph of a rotating DC motor has been incorporated. A controllable voltage source $\boldsymbol{u}$ is imposed across the rotor's winding. 
The electromagnetic coupling is characterized by a torque constant kt. For the mechanical part of the actuator, the inertia of the motor $\mathrm{Jm}$ is considered. A screw-nut system allows a reduction of the velocity with a ratio $1 / K_{S C R E W}$ as well as the transformation of the rotational movement into a translational movement. The operating scheme of the actuation of the moving masses is given in Fig. 26.

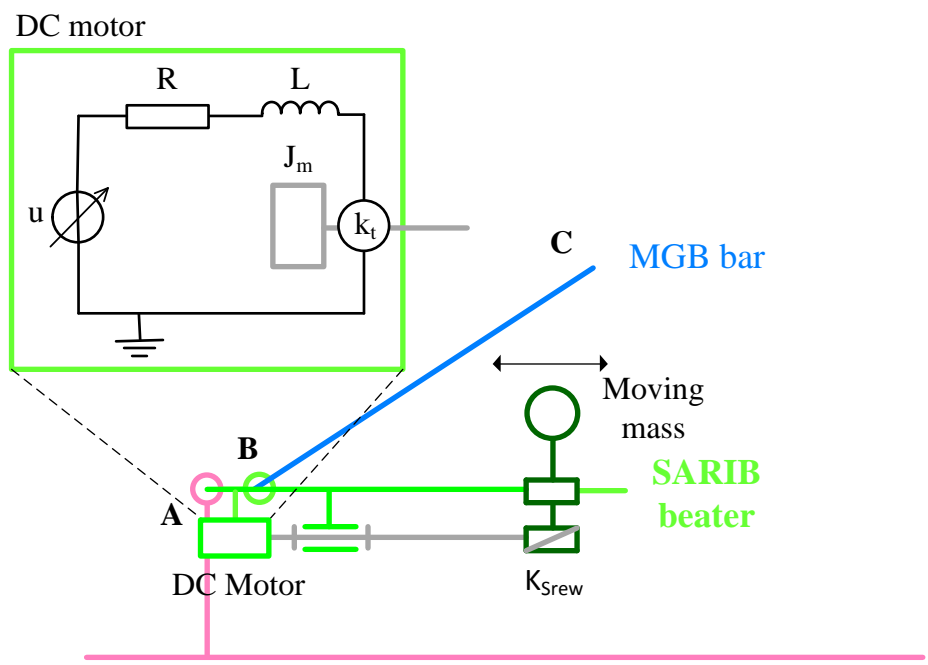

Fuselage

Fig. 26 - Operating scheme of the actuators' moving masses

The bond graph model of the actuated prismatic joint is achieved by connecting the model of the set \{DC motor + screw nut $\}$ at the junction 1 of the degree of freedom related to the movement along the axis of the prismatic joint. Fig.27 details the modeling of the actuated prismatic joint used to drive the moving masses on SARIB beaters.

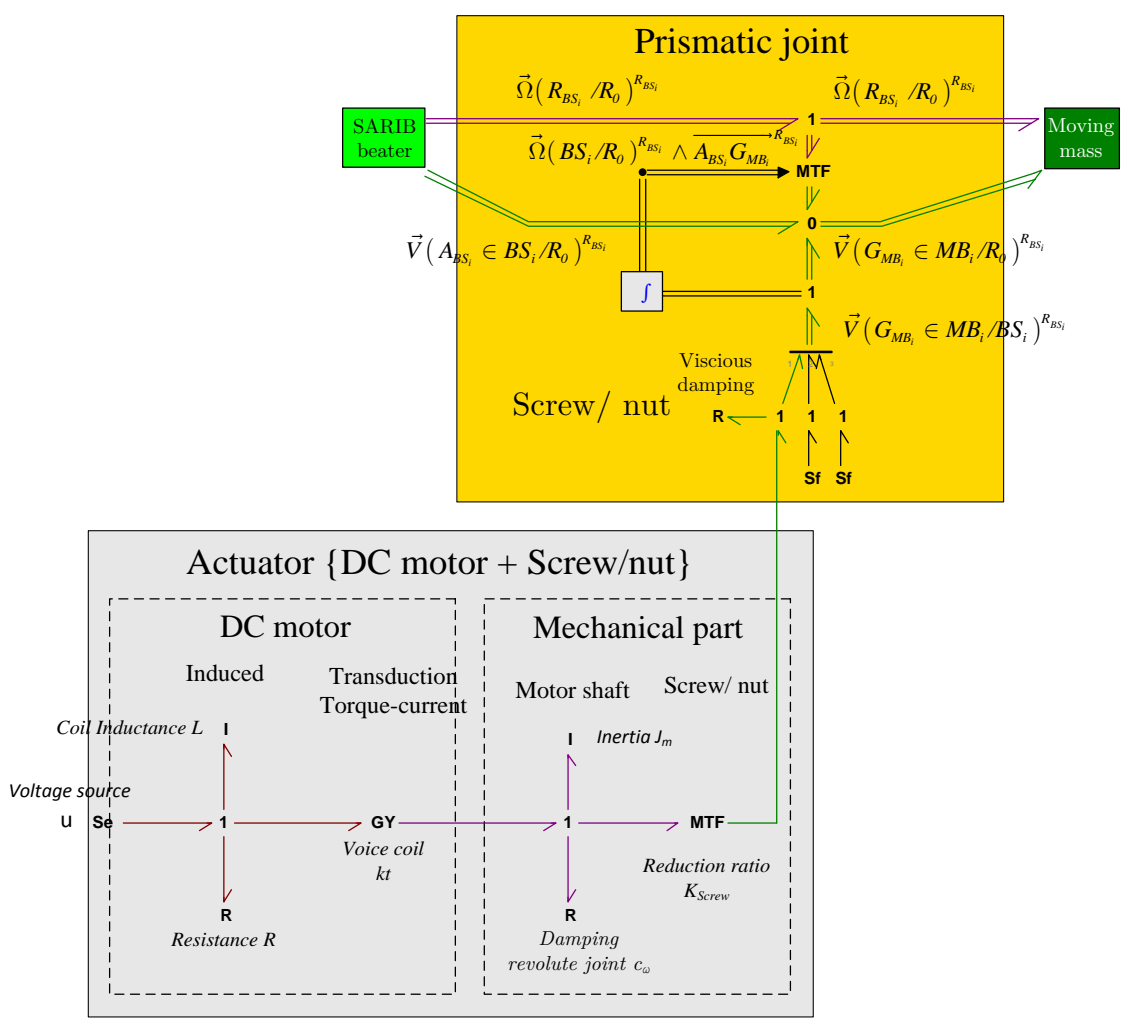

Fig.27 - Bond graph modeling of an actuated prismatic joint 


\subsection{Controller design}

Our control is composed, for each branch, of two loops:

- A strategy control loop for calculating the position setpoints of the moving masses on SARIB beaters. It is the trajectory generation. We used herein a gradient algorithm.

- A position regulation loop for controlling the action of the motors for moving the masses to the positions previously calculated. The objectives of the control loop are to get, in terms of static performance, a response with zero static error and, in terms of dynamic performance, fast enough solution without overshoot.

We begin by discussing the settings of the position control loops prior to the trajectory generation.

\subsubsection{Position regulation loop}

The servo-control of a mass position on an axis is achieved by a control architecture which consists of three nested loops: a current loop, a velocity loop and a position loop. In electrical engineering, this technique is quite classical but recognized as effective because it enables to control easily quantities that do not necessarily have the same dynamic behaviour. The values of the proportional-integral PI correctors used are calculated with the method of poles compensation and the time constant imposition of the transfer functions in closed loops. The values used for the PI controllers are given in the appendix.

The position control loops are used to control the position of the four mobile masses on each SARIB beater. Fig. 28 shows how the four position control loops are linked to the model of the MGB-fuselage joint. The details of a position control loop on a prismatic joint is shown in Fig. 28.

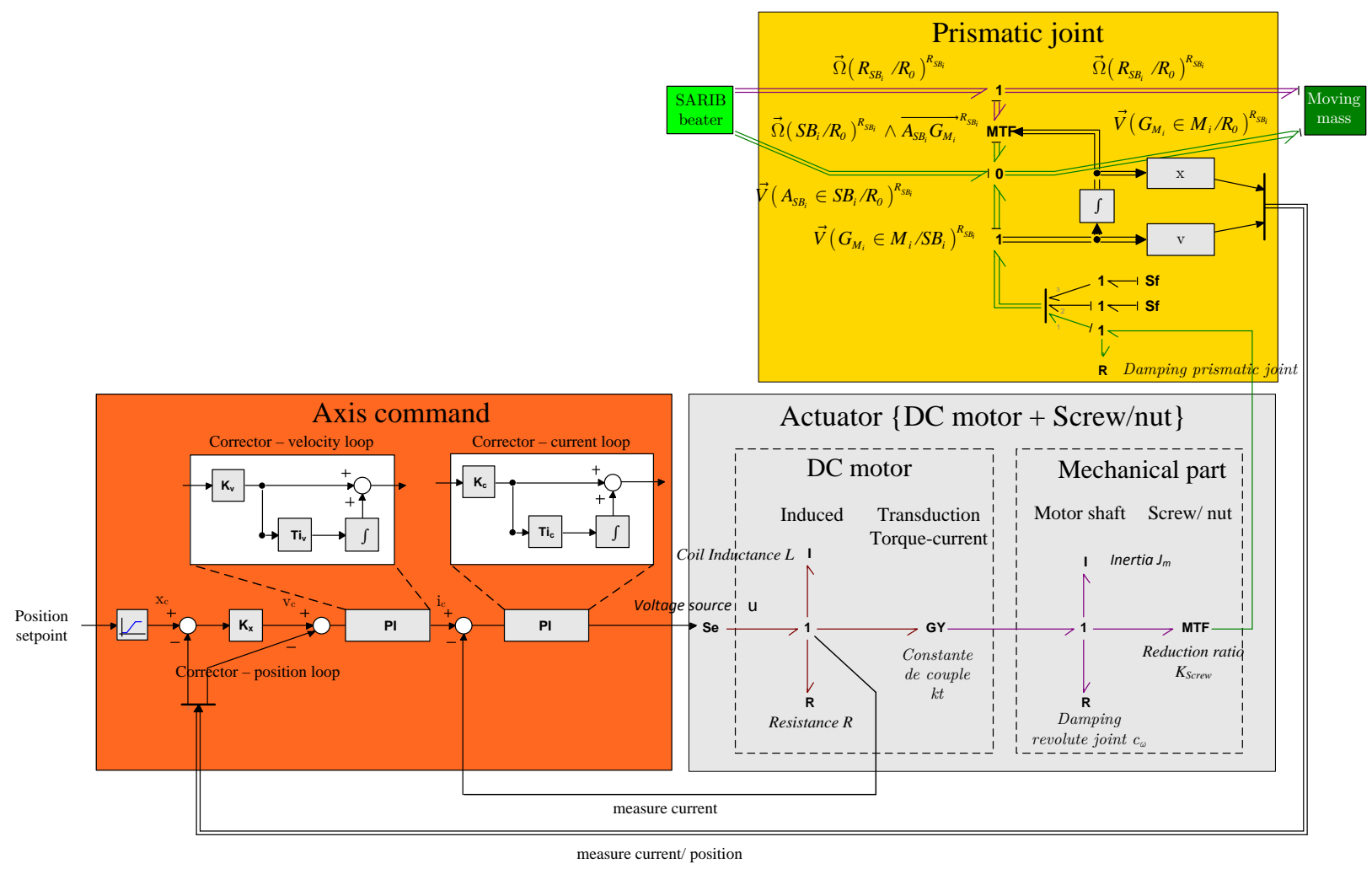

Fig. 28 - Structure of the axis commands

\subsubsection{Command strategy of the position setpoints}

This block is to generate the position setpoints of the moving masses to apply to the four axis controls so as to minimize the vibration level measured at the fuselage. In this section, we consider the case where the MGB is 
subjected only to pumping excitation. The vibration level noted NV was defined as the magnitude of the vertical acceleration of point $\mathrm{O}_{\mathrm{F}}$ of the fuselage. This vibratory level is expressed as follows:

$$
\mathrm{NV}=\mathrm{A}_{z}(t)=\operatorname{amplitude}\left(\mathrm{a}_{z}(\mathrm{t})\right)
$$

The acceleration of the fuselage center depends on the position of the four moving masses. The four moving masses are displaced together synchronously. The vibration level is a non-linear function that depends on the position taken by the masses. Thus, the objective of the control algorithm, expressed in terms of optimization is to determine the position of moving masses (identical outlet for four masses) which minimizes the vertical magnitude of the fuselage center.

In this part, we choose to use an control algorithm already used for the semi-active MGB-fuselage suspension and taken here as the cost function to be minimized: an algorithm based on the constant pitch gradient method. The objective of this study is not here to make a new algorithm for minimizing the vibrational level but to check the ability of the bond graph tool to be used for control of complex mechatronic systems and analyze the benefits of this latter with respect to the methods used so far.

The starting point for the construction of the selected gradient algorithm is the use of a Taylor series expansion truncated to the first order.

$$
\mathrm{A}_{z}(\mathrm{x}(\mathrm{t})+\mathrm{dx}(\mathrm{t}))=\mathrm{A}_{\mathrm{z}}(\mathrm{x}(\mathrm{t}))+\left(\frac{\partial \mathrm{A}_{\mathrm{z}}(\mathrm{x}(\mathrm{t}))}{\partial \mathrm{x}}\right) \mathrm{dx}(\mathrm{t})
$$

The complexity of the function does not allow to express analytically the gradient. Therefore, this function is evaluated by measuring the acceleration for two different positions of the moving masses in the following manner during the simulation:

$$
\left(\frac{\partial \mathrm{A}_{z}}{\partial x}\right)=\frac{\mathrm{A}_{z}\left(\mathrm{x}^{k+1}\right)-\mathrm{A}_{z}\left(\mathrm{x}^{k}\right)}{\mathrm{x}^{k+1}-\mathrm{x}^{k}}
$$

$\mathrm{k}$ is the index related to the discretization. The positions of the moving masses at iteration $\mathrm{k}+1$ are obtained as follows:

$$
x^{k+1}=x^{k}-p \times \operatorname{sign}\left(\left[\frac{\partial \mathrm{A}_{z}}{\partial x}\right]_{x^{k}}\right)
$$

With p a step of progress of the mass [mm]

The control algorithm has been programmed in discrete time as follows:

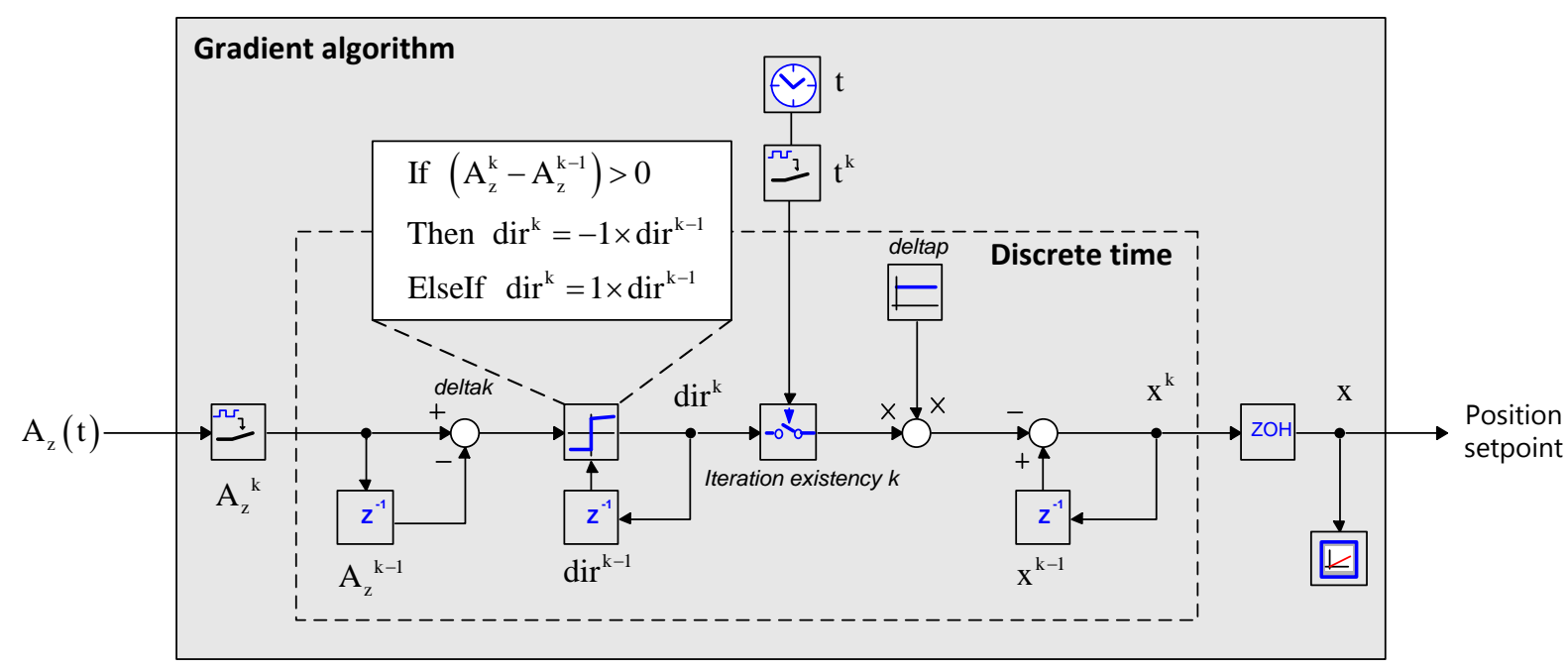

Fig. 29 - Gradient algorithm

The control device comprising the control algorithm and the axis controls of the moving masses is shown in Fig. 30. 


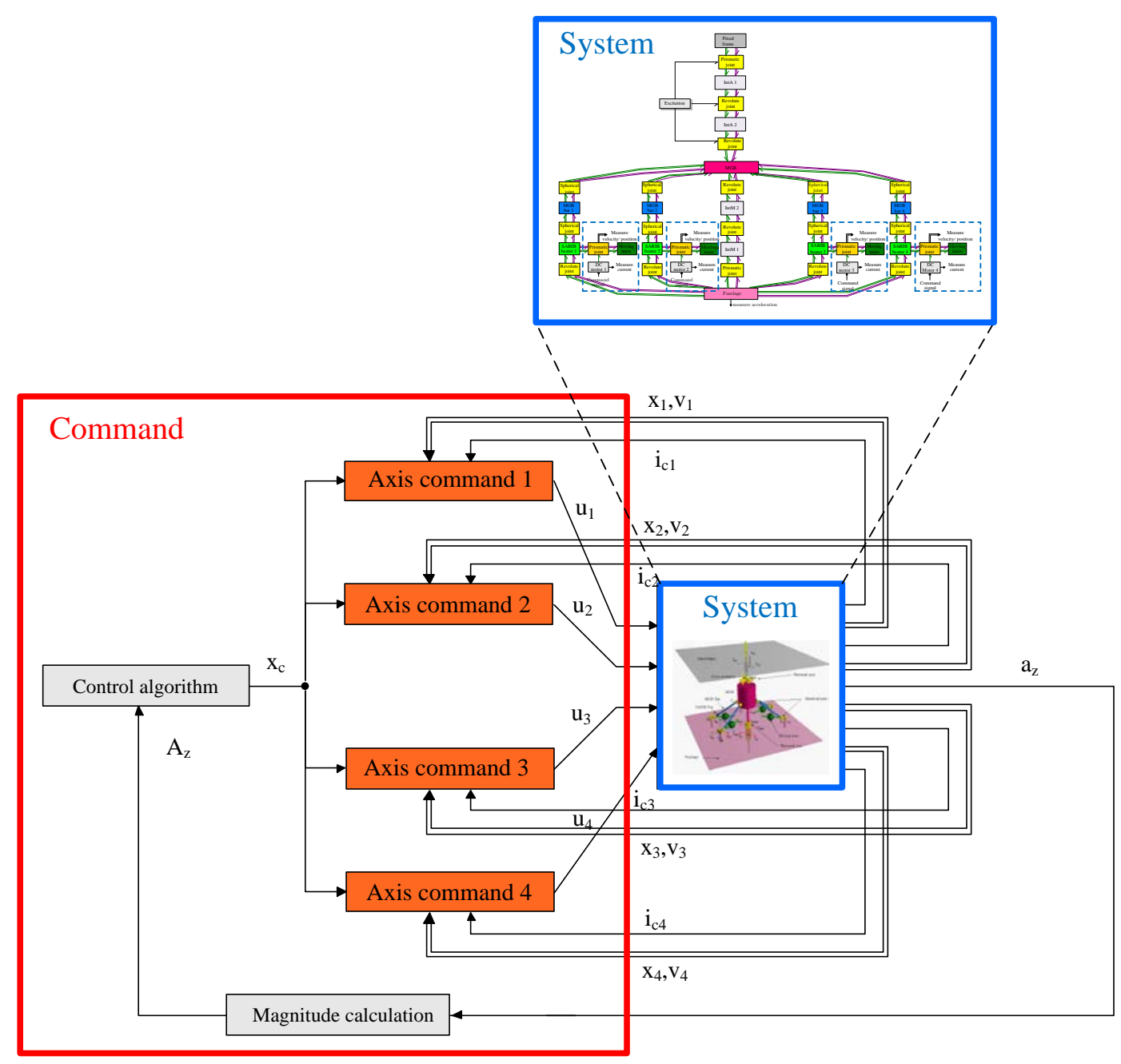

Fig. 30 - Command architecture

\subsection{Results and analysis}

In the case where the MGB is subjected to a sinusoidal excitation in pumping, it is observed that the control algorithm optimizes the level of vibration of the fuselage (Fig. 31). After obtaining a minimum, the moving masses oscillate without diverging around the optimal positions (Fig. 32).

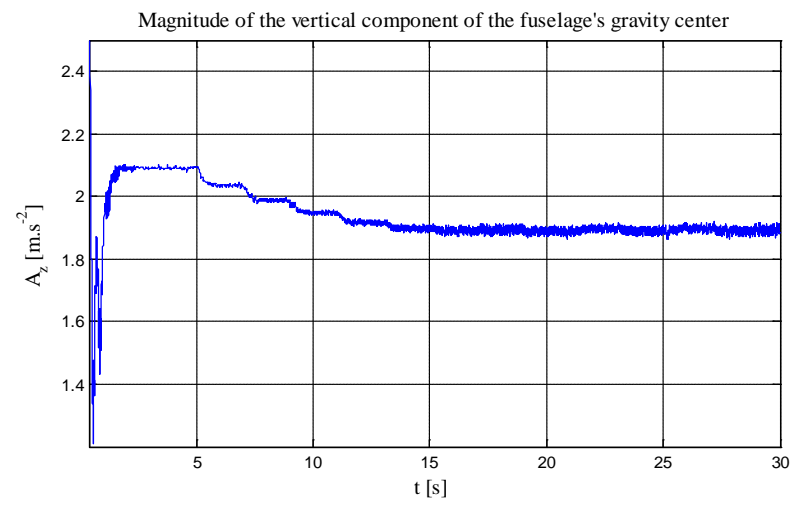

Fig. 31 - Acceleration (a) and magnitude (b) of this acceleration for Ofus 

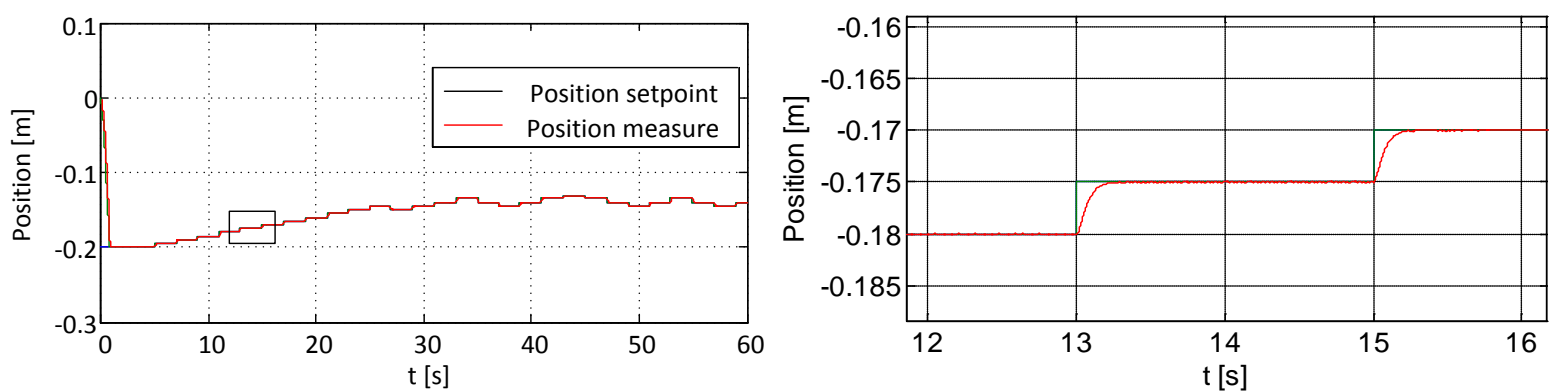

Fig. 32 - Evolution of the position setpoints and position measures of the moving mass (on SARIB beater 1)

The magnitude of the vertical component of the acceleration as a function of the excitation frequency is plotted in two cases: with the moving masses in arbitrary initial positions on the beaters and with the moving masses welltuned on the beaters (Figure 5.61). These curves confirm the correct positions of the moving masses found by the algorithm. Indeed, when the moving masses are in the position determined by the control algorithm, the antiresonance frequency of the vertical component of acceleration of the fuselage is positioned on the excitation frequency of the MGB. Therefore, the vertical magnitude of the acceleration of the fuselage is minimal at the excitation frequency of the MGB.

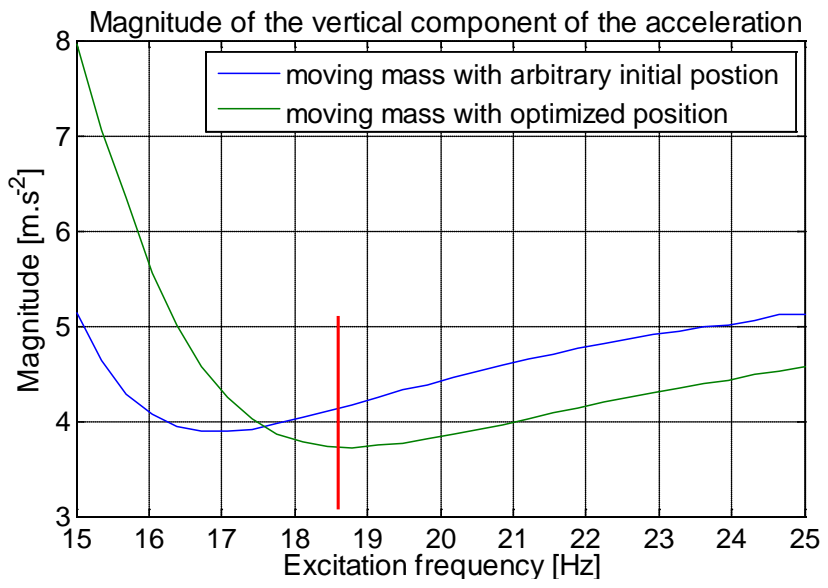

Fig. 33 - Magnitude of the vertical component of the acceleration in function of the excitation frequency

The performed modeling allows to take into account the dynamics of the engines. With the motor data selected for the test bench, the time response is approximately one second. It is easy to estimate the sampling period to choose for the control algorithm and estimate the overall response time of the algorithm.

Moreover, the BG tool permitted to test the command found directly on the nonlinear simulation model.

\section{Conclusion}

A structural and modular approach with bond graph has been presented in this paper so as to model and simulate the dynamics of a complex mechatronic multibody systems: an helicopter's semi-active suspension. The core system is a multibody system with closed kinematic loops. On the top of this, DC motors and and controllers have been implemented.

The proposed methodology consists in the assembly of modules (these components are rigid bodies and kinematic joints) in a similar manner to the real structure of the physical system. This assembly can be easily conducted with the help of a well-structured library of components. Therefore, the constructed multi-body dynamic models permits the representation of a complex system and the bond graph model highlights the topology of systems. To deal with the constraints linked to the vector bonds and the kinematic constraints provided by the joints, the singular perturbation method (adding parasitic compliant elements in the kinematic joints) is used. The singular perturbation method employed in the bond graph model enables to avoid dealing with kinematic constraints equations 
and consequently to have only ODE systems to solve instead of DAEs. Moreover, the simulation of multibody systems with closed kinematic chains may appear easier to conduct than the classic analytical method.

The simulation results of the bond graph model of the studied suspension have been conducted with a dedicated software for bond graphs such as 20-sim. The model of the passive suspension with SARIB system has been verified with another multi-body tool (MapleSim) for three excitations (pumping, roll and yaw) and validated on an experimental setup for the pumping excitation. These simulations have permitted to identify and quantify the anti-resonance which were sought so as to filter the vibrations coming from the rotor to the fuselage.

Finally, the ability to integrate models of electrical systems and controls device to the multi-body model model in the same modeling environment have been tested. For that purpose, the bond graph model was used for the establishment of a semi-active control device. This model has also been developed with 20-sim and allows to adjust the position of the moving masses in operation so as to minimize the level of vibration of the fuselage. The control algorithm (gradient algorithm) enables to calculate the setpoint positions of the moving masses on the DAVI beaters. The position of the moving masses driven by an electric DC motor and a screw-nut system has been optimized and PI controllers have permitted to position the moving masses to the setpoints generated by the control algorithm. Due to the intrinsic characteristics of bond graph, this tool provides a detailed vision of the modeled system where decomposition of the modules elements shows the selected role models and modeling assumptions made explicit. For example, it would be easy to take into account the influence of the engine friction behavior law on its dynamics and its impact in the control set up. Finally, bond graphs can be used to test the control command directly on the non-linear simulation model.

\section{Acknowledgments}

This research work received support from the Chair "Dynamics of complex mechanical systems - EADS Corporate Foundation - Arts et Métiers ParisTech and Ecole Centrale de Marseille.".

Thanks to Paul B.T. Weustink working as Controllab Products for his help on the use of complementary tools of 20-sim software.

\section{Appendix : modeling data of the experimental setup of the semi-active suspension}

\section{Geometry}

\begin{tabular}{|c|c|c|c|c|c|c|}
\hline \multicolumn{7}{|c|}{ Fuselage } \\
\hline & $\mathrm{X}(\mathrm{mm})$ & $\mathrm{Y}(\mathrm{mm})$ & $\mathrm{Z}(\mathrm{mm})$ & $\mathrm{a}_{\mathrm{Fi}}(\mathrm{rad})$ & $\mathrm{a}_{\mathrm{Fi}}(\mathrm{deg})$ & $\mathrm{Rf}_{\mathrm{i}}$ \\
\hline $\mathrm{G}_{\text {Fus }}$ & 0.000 & 0.000 & 0.000 & & & \\
\hline Fittings ARD $\left(\mathrm{A}_{1}\right)$ & 460.718 & 222.399 & 217.054 & 0.45 & 25.77 & 511.588 \\
\hline Fittings ARG $\left(\mathrm{A}_{2}\right)$ & 460.718 & -222.399 & 217.054 & -0.45 & -25.77 & 511.588 \\
\hline Fittings AVG $\left(\mathrm{A}_{3}\right)$ & -460.718 & -222.399 & 217.054 & 3.59 & 205.77 & 511.588 \\
\hline Fittings AVD $\left(\mathrm{A}_{4}\right)$ & -460.718 & 222.399 & 217.054 & 2.69 & 154.23 & 511.588 \\
\hline $\mathrm{O}_{\text {Fus }}$ & 0.000 & 0 & 56.054 & & & 0.00 \\
\hline \multicolumn{7}{|c|}{$\begin{array}{l}\text { MGB } \\
\end{array}$} \\
\hline & $\mathrm{X}(\mathrm{mm})$ & $\mathrm{Y}(\mathrm{mm})$ & $\mathrm{Z}(\mathrm{mm})$ & & & \\
\hline $\mathrm{G}_{\mathrm{MGB}}$ & 0.00 & 0.00 & 0.00 & & & \\
\hline Attach center ARD $\left(\mathrm{C}_{1}\right)$ & 99.992 & 70 & -199 & & & \\
\hline Attach center ARG $\left(\mathrm{C}_{2}\right)$ & 99.992 & -70 & -199 & & & \\
\hline Attach center AVG $\left(\mathrm{C}_{3}\right)$ & -100.008 & -70 & -199 & & & \\
\hline Attach center AVD $\left(\mathrm{C}_{4}\right)$ & -100.008 & 70,00 & -199 & & & \\
\hline $\mathrm{A}_{\mathrm{MGB}}$ & 0.000 & 0.000 & 336.0 & & & \\
\hline $\mathrm{O}_{\mathrm{MGB}}$ & -0.008 & 0.000 & -449.0 & & & \\
\hline \multicolumn{7}{|c|}{ MGB bars } \\
\hline $\mathrm{BC}(\mathrm{mm})$ & 400 & & & & & \\
\hline
\end{tabular}




\begin{tabular}{llll}
\hline $\mathrm{BG}_{\mathrm{MB}}(\mathrm{mm})$ & 200 & \multicolumn{2}{c}{ SARIB beaters } \\
\hline \hline $\mathrm{AB}(\mathrm{mm})$ & 50 & & \\
\hline & $\mathrm{X}(\mathrm{mm})$ & $\mathrm{Y}(\mathrm{mm})$ & $\mathrm{Z}(\mathrm{mm})$ \\
\hline $\mathrm{G}_{\mathrm{SB}}$ & 0.00 & 0.00 & 0.00 \\
\hline $\mathrm{A}$ & -106.174 & 0 & -28.195 \\
\hline \hline
\end{tabular}

\section{Initial conditions}

\section{MGB}

\begin{tabular}{|c|c|}
\hline Initial position $\mathrm{G}_{\mathrm{MGB}}[\mathrm{m}]$ & {$[0.7000000000 \mathrm{e}-5,0,-.5359930000]^{\mathrm{T}}$} \\
\hline Euler angles MGB [rad] & {$[0,0,0]^{\mathrm{T}}$} \\
\hline \multicolumn{2}{|r|}{ Fuselage } \\
\hline Initial position $\mathrm{G}_{\mathrm{F}}[\mathrm{m}]$ & {$[0 ., 0 .,-1.160006000]^{\mathrm{T}}$} \\
\hline Euler angles F [rad] & {$[0,0,0]^{\mathrm{T}}$} \\
\hline \multicolumn{2}{|r|}{ MGB bars } \\
\hline Initial position $\mathrm{G}_{\mathrm{MB} 1}[\mathrm{~m}]$ & {$[0.2578448918,0.1353314307,-0.8390038188]^{\mathrm{T}}$} \\
\hline Euler angles MB1 [rad] & {$[-0.2591385106,0.4880132457,0.4656506145]^{\mathrm{T}}$} \\
\hline Initial position $\mathrm{G}_{\mathrm{MB} 2}[\mathrm{~m}]$ & {$[0.2578448918,-0.1353314307,-0.8390038188]^{\mathrm{T}}$} \\
\hline Euler angles MB2 [rad] & {$[0.2591385106,0.4880132457,-0.4656506145]^{\mathrm{T}}$} \\
\hline Initial position $\mathrm{G}_{\mathrm{MB} 3}[\mathrm{~m}]$ & {$[-0.2578448917,-0.1353314307,-0.8390038188]^{\mathrm{T}}$} \\
\hline Euler angles MB3 [rad] & {$[0.2591385108,-0.4880132457,-2.675942039]^{\mathrm{T}}$} \\
\hline Initial position $\mathrm{G}_{\mathrm{MB} 4}[\mathrm{~m}]$ & {$[-0.2578448917,0.1353314307,-0.8390038188]^{\mathrm{T}}$} \\
\hline Euler angles MB4 [rad] & {$[-0.2591385108,-0.4880132457,2.675942039]^{\mathrm{T}}$} \\
\hline \multicolumn{2}{|r|}{ SARIB beaters } \\
\hline Initial position $\mathrm{G}_{\mathrm{SB} 1}[\mathrm{~m}]$ & {$[0.3651023145,0.1762431458,-0.9712044772]^{\mathrm{T}}$} \\
\hline Euler angles SB1 [rad] & {$[0.00001423717080,-0.00002949348177,0.4497304165]^{\mathrm{T}}$} \\
\hline Initial position $\mathrm{G}_{\mathrm{SB} 2}[\mathrm{~m}]$ & {$[0.3651023145,-00.1762431458,-00.9712044772]^{\mathrm{T}}$} \\
\hline Euler angles SB2 [rad] & {$[-0.00001423717080,-0.00002949348177,-0.4497304165]^{\mathrm{T}}$} \\
\hline Initial position $\mathrm{G}_{\mathrm{SB} 3}[\mathrm{~m}]$ & {$[-0.3651023144,-0.1762431459,-0.9712044772]^{\mathrm{T}}$} \\
\hline Euler angles SB3 [rad] & {$[-0.00001423717081,0.00002949348177,-2.691862237]^{\mathrm{T}}$} \\
\hline Initial position $\mathrm{G}_{\mathrm{SB} 4}[\mathrm{~m}]$ & {$[-0.3651023144,0.1762431459,-0.9712044772]^{\mathrm{T}}$} \\
\hline Euler angles SB4 [rad] & {$[0.00001423717081,0.00002949348177,2.691862237]^{\mathrm{T}}$} \\
\hline
\end{tabular}

\section{Masses and inertia}

\begin{tabular}{lllll}
\hline \hline Parameters & MGB & Fuselage & SARIB beaters & MGB bars \\
\hline \hline Mass $(\mathrm{kg})$ & 128.347 & 987.686 & 4.756 & 0.001 \\
\hline$I_{x x}\left(\mathrm{~kg} \cdot \mathrm{m}^{2}\right)$ & 7.720 & 38.210 & 0.005 & 0.001 \\
\hline$I_{y y}\left(\mathrm{~kg} \cdot \mathrm{m}^{2}\right)$ & 7.598 & 327.303 & 0.079 & 0.001 \\
\hline$I_{z z}\left(\mathrm{~kg} \cdot \mathrm{m}^{2}\right)$ & 2.251 & 362.421 & 0.077 & 0.001 \\
\hline
\end{tabular}

\section{Stiffnesses and damping}

\begin{tabular}{llll}
\hline \hline Joints & Description & Stiffness & Damping \\
\hline \hline \multirow{3}{*}{ Attach joint } & Pumping & $100000(\mathrm{~N} / \mathrm{m})$ & $5000(\mathrm{~N} . \mathrm{s} / \mathrm{m})$ \\
\cline { 2 - 4 } & Yaw & $0.001(\mathrm{~N} . \mathrm{m} / \mathrm{rad})$ & $2(\mathrm{~N} . \mathrm{m} . \mathrm{s} / \mathrm{rad})$ \\
\cline { 2 - 4 } & Roll & $0.001(\mathrm{~N} . \mathrm{m} / \mathrm{rad})$ & $2(\mathrm{~N} . \mathrm{m} . \mathrm{s} / \mathrm{rad})$ \\
\hline
\end{tabular}




\begin{tabular}{llll}
\hline \multirow{3}{*}{ Membrane } & Pumping & $0.001(\mathrm{~N} / \mathrm{m})$ & $2(\mathrm{~N} . \mathrm{s} / \mathrm{m})$ \\
\cline { 2 - 4 } & Yaw & $0.001(\mathrm{~N} . \mathrm{m} / \mathrm{rad})$ & $2(\mathrm{~N} . \mathrm{m} . \mathrm{s} / \mathrm{rad})$ \\
\cline { 2 - 4 } & Roll & $0.001(\mathrm{~N} . \mathrm{m} / \mathrm{rad})$ & $2(\mathrm{~N} . \mathrm{m} . \mathrm{s} / \mathrm{rad})$ \\
\hline 4 revolute joints between & Torsion springs & $1190(\mathrm{~N} . \mathrm{m} / \mathrm{rad})$ & $2(\mathrm{~N} . \mathrm{s} / \mathrm{m})$ \\
SARIB beaters and fuselage & & &
\end{tabular}

\begin{tabular}{lll}
\hline \hline Other & & \\
\hline \hline Virtual springs & $10^{10}(\mathrm{~N} / \mathrm{m})$ or $(\mathrm{N} . \mathrm{m} / \mathrm{rad})$ & 200 (N.s/m) or $(\mathrm{N} . \mathrm{m} . \mathrm{s} / \mathrm{rad})$ \\
\hline
\end{tabular}

\section{Actuators}

Les principales grandeurs du dispositif qui proviennent des composants choisis pour le banc d'essai sont données dans le tableau suivant :

\begin{tabular}{llll}
\hline \hline Components & Parameters & Values & Units \\
\hline \hline \multirow{4}{*}{ DC motor } & Resistance R & 12.4 & $\Omega$ \\
\cline { 2 - 4 } & Inductance L & 0.488 & $\mathrm{mH}$ \\
\cline { 2 - 4 } & Torque constant $\mathrm{k}_{\mathrm{t}}$ & 0.0181 & $\mathrm{~N} \cdot \mathrm{m}_{\mathrm{A}} \mathrm{A}^{-1}$ \\
\cline { 2 - 4 } & Friction coefficient $C_{\omega}$ & 0.0027 & $\mathrm{~N} \cdot \mathrm{m}^{-1} \mathrm{rad}^{-1} \cdot \mathrm{s}^{-1}$ \\
\cline { 2 - 4 } & Inertia $\mathrm{J}_{\mathrm{m}}$ & $2.25 .10^{-7}$ & $\mathrm{~kg} \cdot \mathrm{m}^{2}$ \\
\hline Screw-nut & Reduction ratio $\mathrm{K}_{\text {vis }}$ & 0.019 & -- \\
\hline
\end{tabular}

\section{PI controllers' values}

\begin{tabular}{llll}
\hline \hline Feedback loops & Current & Velocity & Position \\
\hline \hline Gain & $\mathrm{K}_{\mathrm{c}}=124$ & $\mathrm{~K}_{\mathrm{v}}=78.1$ & $\mathrm{~K}_{\mathrm{x}}=13.3$ \\
\hline Time constant & $\mathrm{Ti}_{\mathrm{c}}=3.935 .10^{-5}(\mathrm{~s})$ & $\mathrm{Ti}_{\mathrm{v}}=0.187(\mathrm{~s})$ & -- \\
\hline
\end{tabular}

\section{References}

[1] W. SCHIEHLEN, "Research trends in multibody system dynamics," Multibody System Dynamics, vol. 18, pp. 3-13, 2007/08/01 2007.

[2] J. v. AMERONGEN and P. BREEDVELD, "Modelling of physical systems for the design and control of mechatronc systems," Annual review in Control, 2003.

[3] W. XU, Y. LIU, B. LIANG, X. WANG, and Y. XU, "Unified multi-domain modelling and simulation of space robot for capturing a moving target," Multibody System Dynamics, vol. 23, pp. 293-331, 2010/03/01 2010.

[4] H. M. PAYNTER, Analysis and Design of Engineering systems: MIT Press, 1961.

[5] W. BORUTSKY, Bond Graph Methodology - Development and Analysis of Multidisciplinary Dynamic System Models, Springer ed., 2010.

[6] L. SASS, J. McPHEE, C. SCHMITKE, P. FISETTE, and D. GRENIER, "A Comparison of Different Methods for Modelling Electromechanical Multibody Systems," Multibody System Dynamics, vol. 12, pp. 209-250, 2004/10/01 2004.

[7] M. J. L. TIERNEGO and A. M. BOS, "Modelling the dynamics and kinematics of mechanical systems with multibond graphs," Journal of the Franklin Institute, vol. 319, pp. 37-50, 1985.

[8] A. M. BOS, "Multibody Systems in Terms of Multibond Graphs with Application to a Motorcycle Multibody system," University of Twente, Enschede, The Netherlands, 1986.

[9] V. ABADIE, F. GUILLEMARD, and A. RAULT, "Apport du bond graph dans la démarche mécatronique appliquée à l'automobile," in Les bond graphs, G. DAUPHIN-TANGUY, Ed., ed: Hermès Sciences, 2000.

[10] A. ZEID and C.-H. CHUNG, "Bond graph modeling of multibody systems: a library of three-dimensional joints," Journal of the Franklin Institute, vol. 329, pp. 605-636, 1992. 
[11] A. A. ZEID and J. L. OVERHOLT, "Singularly perturbed formulation : explicit modeling of multibody systems," Journal of The Franklin Institute, 1995.

[12] J. WANG, C. GOSSELIN, and L. CHENG, "Modeling and Simulation of Robotic Systems with Closed Kinematic Chains Using the Virtual Spring Approach," Multibody System Dynamics, pp. 145-170, 2001.

[13] T. KRYSINSKI and F. MALBURET, Mechanical Vibrations: Active and Passive Control: Wiley-Iste, 2006.

[14] D. C. KARNOPP, D. L. MARGOLIS, and R. C. ROSEMBERG, System Dynamics - Modeling and Simulation of Mechatronics Systems, John Wiley \& Sons ed., 2000.

[15] M. TILLER, Introduction to Physical Modeling with Modelica: Kluwer Academic Publishers, 2001.

[16] W. MARQUIS-FAVRE and A. JARDIN, "Bond Graphs and Inverse Modeling for Mechatronic System Design," in Bond graph modeling of engineering systems, W. BORUTSKY, Ed., ed: Springer, 2011.

[17] J. FELEZ, G. ROMERO, J. MAROTO, and M. L. MarTINEZ, "Simulation of multi-body systems using multi-bond graph," in Bond graph modeling of engineering systems, W. BORUTSKY, Ed., ed: Springer, 2011.

[18] D. Karnopp, "Power-conserving transformations: physical interpretations and applications using bond graphs," Journal of the Franklin Institute, vol. 288, pp. 175-201, 9// 1969.

[19] R. C. ROSENBERG, "Multiport models in mechanics," Journal of Dynamic Systems, Measurement and Control, pp. 206-212, 1972.

[20] L. S. BONDERSON, "Vector bond graphs applied to one-dimensional distributed systems," Journal of Dynamic Systems, Measurement and Control, vol. 1 pp. 75-82, 1975.

[21] P. C. BREEDVELD, "Multibond graph elements in physical systems theory," Journal of Franklin Institute, vol. 319, pp. 1-36, 1985.

[22] J. FELEZ, C. VERA, I. SAN JOSE, and R. CACHO, "BONDYN : a bond graph based simulation program for multibody systems," Journal of Dynamic Systems, Measurement and Control, 1990.

[23] J. VAN DIJK and P. C. BREEDVELD, "Simulation of system models containing zero-order causal paths-I. Classification of zero-order causal paths," Journal of the Franklin Institute, vol. 328, pp. 959979, // 1991.

[24] J. VAN DIJK and P. C. BREEDVELD, "Simulation of system models containing zero-order causal paths-II Numerical implications of class 1 zero-order causal paths," Journal of the Franklin Institute, vol. 328, pp. 981-1004, // 1991.

[25] W. MARQUIS-FAVRE and S. SCAVARDA, "Bond graph representation of multibody systems with kinematic loops," Journal of the Franklin Institute, vol. 335B, pp. 643-660, 1998.

[26] J. C. SAMIN, O. BRULS, J. F. COLLARD, L. SASS, and P. FISETTE, "Multiphysics modeling and optimization of mechatronic multibody systems," Multibody System Dynamics, vol. 18, pp. 345-373, 2007/10/01 2007.

[27] T. ERSAL, J. L. STEIN, and L. S. LOUCA, "A Bond Graph Based Modular Modeling Approach Towards an Automated Modeling Environment for Reconfigurable Machine Tools," in IMAACA, Genea, Italy, 2004.

[28] S. BEHZADIPOUR and A. KHAJEPOUR, "Causality in vector bond graphs and its application to modeling of multi-body dynamic systems," Simulation Modelling Practice and Theory, pp. 279-295, 2005.

[29] W. MARQUIS-FAVRE, "Simulation des mécanismes : Résolution des équations dans les logiciels," Techniques de l'ingénieur, 2007.

[30] T. K. UCHIDA, "Real-tim Dynamic Simulation of Constrained Multibody Systems using Symbolic Computation," Systems Design Engineering, University of Waterloo, Ontario, 2011.

[31] G. RIDEOUT, "System partitioning and physical domain proper modeling through assessment of powerconserving model structure," Thèse de doctorat, University of Michigan, 2004.

[32] T. RAYMAN, G. RIDEOUT, and N. KROUGLICOF, "Evaluation of Dynamic Performance of NonSpherical Parallel Orientation Manipulators through Bond Graph Multi-Body Simulation," in Bond Graph Modeling Genoa, Italy, 2012.

[33] M. Lalanne, Vibrations et chocs mécaniques Tome 1 : Vibrations sinoïdales: Hermès, 1999.

[34] W. MARQUIS-FAVRE, "Contribution à la représentation bond graph des systèmes mécaniques multicorps," Thèse de doctorat, Automatique, INSA de Lyon, 1997. 